\title{
Article \\ Preliminary Design and Experimental Study of a Steel-Batten Ribbed Cable Dome
}

\author{
Mingmin Ding ${ }^{1}\left(\mathbb{D}\right.$, Yuzhou Shen ${ }^{2}$, Yang Wei ${ }^{1, *}{ }^{-}$, Bin Luo $^{2, *} \mathbb{0}$, Lulu Wang ${ }^{1}$ and Ningyuan Zhang ${ }^{2}$ \\ 1 College of Civil Engineering, Nanjing Forestry University, Nanjing 210037, China; \\ dmm1989@njfu.edu.cn (M.D.); wl11997@njfu.edu.cn (L.W.) \\ 2 National Prestress Engineering Research Center, Key Laboratory of C \& PC Structures, Ministry of Education, \\ Southeast University, Nanjing 210096, China; yzshen@seu.edu.cn (Y.S.); zny96@seu.edu.cn (N.Z.) \\ * Correspondence: wy78@njfu.edu.cn (Y.W.); seurobin@seu.edu.cn (B.L.)
}

Citation: Ding, M.; Shen, Y.; Wei, Y.; Luo, B.; Wang, L.; Zhang, N. Preliminary Design and Experimental Study of a Steel-Batten Ribbed Cable Dome. Symmetry 2021, 13, 2136. https://doi.org/10.3390/sym13112136

Academic Editor: Jan Awrejcewicz

Received: 7 October 2021

Accepted: 2 November 2021

Published: 10 November 2021

Publisher's Note: MDPI stays neutral with regard to jurisdictional claims in published maps and institutional affiliations.

Copyright: (c) 2021 by the authors. Licensee MDPI, Basel, Switzerland. This article is an open access article distributed under the terms and conditions of the Creative Commons Attribution (CC BY) license (https:// creativecommons.org/licenses/by/ $4.0 /)$.

\begin{abstract}
A steel-batten ribbed cable dome structural system is proposed. By replacing the upper flexible cables with semi-rigid steel battens, rigid roofing materials were conveniently installed overhead via non-bracket or less-bracket technology. Additionally, an $8 \mathrm{~m}$ diameter test model was designed, and a ' $\omega$ ' shaped less-bracket consequent hoist-dragging system was adopted. Finally, the test model was tested under symmetric and asymmetric uniform loading arrangements, while a finite element model was established to verify the test values. The results indicate that the measured values are basically consistent with the finite element values. In the early steps of hoisting and dragging, the structure establishes a prestress, accumulates stiffness, and found its internal force balance, while the entire structure keeps a " $\omega$ " shape to guarantee stability. As the internal forces of the components increase, the structure turns from " $\omega$ " to " $\mathrm{m}$ " and finally reached its designed shape. With increasing symmetric uniform load, the internal forces of the cables decrease, the bending stresses of the steel battens increase, and the steel battens remain in the elastic stage. Under an asymmetric uniform load, the high loaded area is displaced downward, and the low loaded area behaves upward, twisting the overall structure.
\end{abstract}

Keywords: steel-batten ribbed cable dome; less-bracket hoist-dragging construction; model experiment; static performance; finite element simulation

\section{Introduction}

Due to their excellent spanning ability and low weight, and clear transmission path, cable domes [1] have been extensively studied and used in various engineering projects, such as stadiums [2,3], airports, and exhibition centers [4]. A traditional cable dome is composed of ridge cables (i.e., cable-net dome) and bottom cable-strut system. In terms of the forms of ridge cables, cable domes could be classified into several categories ribbed cable dome, Levy cable dome, Kiewitt cable dome, etc. Among them, relatively clearer force transmission path makes ribbed cable dome more popular. Furthermore, different from trusses [5,6], suspen-domes [7] or single-layer reticulated shells, the initial prestress in cables and struts provides the cable-strut system rigidity, making it resistant to external loads from the roofing plates [8], and thus, improves the bearing capacity and out-of-plane stability of the entire structure.

Currently, roofing materials of large-span structures mainly contains two types: flexible materials and rigid materials. To make the appearance light and concise, the distance between adjacent ridge cables of a cable dome is always designed to be large, which is a large challenge to the spanning ability of roofing plates. As a result, most of existing cable domes are covered with flexible membranes or inflated cushions [9]. However, the current domestic climate and environmental conditions impose higher durability and self-cleaning requirements on membrane materials, which make the construction and maintenance costs 
higher when using flexible membranes as dome plates, hindering the application of cable domes to a certain extent.

Traditional rigid roofing materials, such as glass panels [10], profiled steel plates [11], and aluminum magnesium manganese plates, which have reasonable forms of force transmission, are beneficial for roof insulation, pollution resistance, and construction convenience and have been widely used in buildings $[12,13]$. However, when applying rigid roofing panels to cable structures, the connection joint between the cable body and the roofing plates requires special measures, which are often complex in structure and complicated in construction and thus increase the total cost of structural construction.

Extensive research has been conducted to lay rigid plates on tensile structures. A suspended dome [14] is a hybrid structure, with a reticulated steel shell for laying rigid roofing plates and a cable-strut system for improving the structure's out-of-plane stiffness. However, under the vertical load, the rigid members in the upper part of the structure are compressed and bent. In order to improve the stability, the section sizes of these members are larger, which significantly increases the total weight of the main structure. The existing rigid roof cable dome projects are being conducted at the Wuxi New District Science and the Technology Exchange Center and Coal Trading Center of China. Both of these projects use a sub-grid to support the upper rigid plates. The secondary sub-grid structure is often placed on the top of the strut, which increases the complexity of the nodal joints of the struts and places higher requirements on the anti-sliding of the cable clamp [15]. More recently, Ding et al. [16] proposed a Geiger-type ridge-beam cable dome, which changes the ridge cables of a traditional cable dome to rigid beams. However, to fulfill the requirements of integral tow-lifting construction, the ridge beams are articulated at both ends and the middle nodes, which leads to large local deformations under vertical loads. In addition, because the span of the large-span roofs generally reaches up to tens or even hundreds of meters [17] and the span of rigid roof panels is generally small, it is difficult to lay rigid roof panels directly between the adjacent tension beams.

Based on the above aspects, a steel-batten ribbed cable dome (SBRD), which is suitable for rigid roofing systems by replacing ridge cables of conventional cable domes with semi-rigid steel battens, is proposed and preliminary designed in this paper. As a new type of structure, the SBRD is in a soft state without prestress, which is suitable for the requirements of less-bracket consequent hoist-dragging construction. Nevertheless, some key problems of the SBRD still need to be solved before it can be used in practice:

1. The steel battens and bottom cable-strut system must be coordinated.

2. The deformation mode of the SBRD should be investigated to ensure the stability of the entire structure in less-bracket consequent hoist-dragging construction.

3. The stiffness and load-carrying capacity of the SBRD should be understood, and it should be ensured that the SBRD satisfies the practical requirements in actual projects.

In this study, a summary is stated to introduce the characteristics of the SBRD. Then, an $8 \mathrm{~m}$ specimen is built and monitored to investigate the structural configurations in the different steps of the less-bracket consequent hoist-dragging construction. Finally, the structural behaviors of the SBRD are obtained by testing the specimen in both the symmetric and asymmetric uniform loading cases.

\section{Steel-Batten Ribbed Cable Dome (SBRD)}

\subsection{Structural Composition}

SBRDs are created by replacing the ridge cables of traditional cable domes by narrow and thin steel plates. Similar to traditional cable domes, an SBRD consists of an inner compression ring, slanting cables, struts, ring cables, and steel battens (shown in Figure 1). The steel battens are made of long hot-rolled steel plates with relatively higher tensile strength than traditional steel components. As the thickness of a steel batten is much smaller than its length, the steel battens are flexible without much stiffness similar to ordinary cables when not tensioned. Therefore, advanced construction methods of cable domes such as tow-lifting construction technology can be used for new structures [18]. 
However, if the SBRD is tensioned, then a prestress distribution is generated, and the mechanism system becomes a rigid structure to bear external loads. Then, the rigid roof can be installed on the tensioned steel battens with high-strength bolts and nuts. The holes for the bolts are opened when the steel battens are produced.

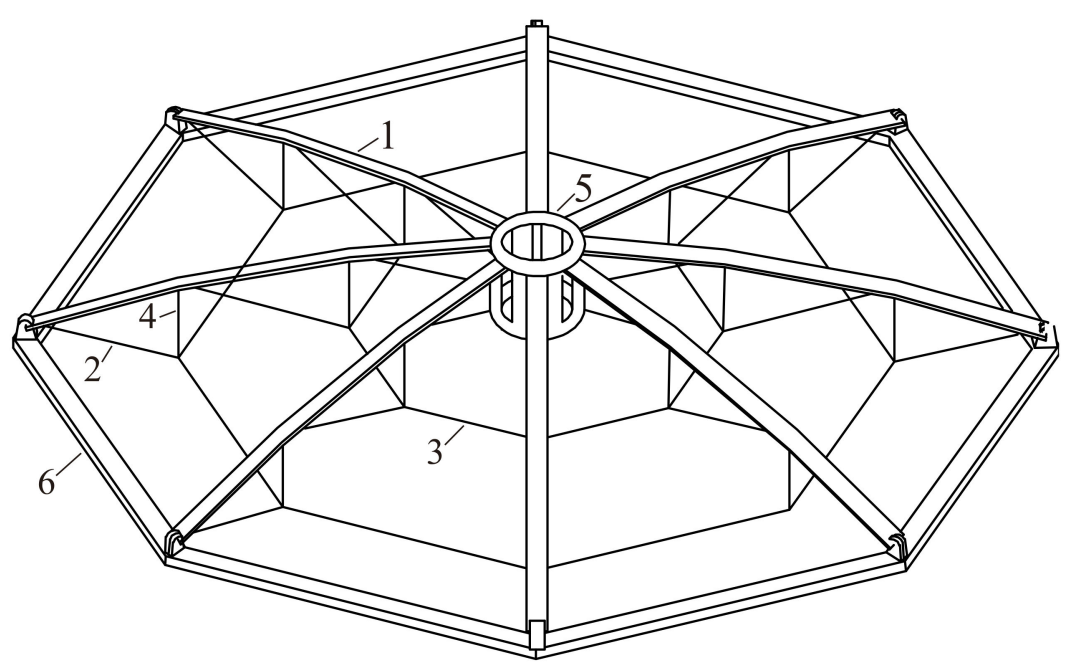

Figure 1. Steel-batten ribbed cable dome (SBRD) (1. steel batten; 2 . slanting cable; 3 . hoop cable; 4. strut; 5 . inner compression ring; 6. outer compression beam).

\subsection{Connecting Joint}

To meet the structural demand of the tensile strength, several steel battens are overlapped up and down and fixed together by high-strength bolts to act as one component. With only a few steel cover plates, connecting plates and high-strength bolts, a joint between the steel battens, struts and slanting cables can be easily established. As shown in Figure $2 \mathrm{a}$, a strut and an adjacent slanting cable are connected to a connecting plate through the hinge pin, and a cover plate is set on the steel batten. The cover plate, steel batten and connecting plate are fixed together by high-strength bolts, with adequate pretension forces.

When using less-bracket consequent hoist-dragging construction technology, the installation of the connections can be conducted on the ground before the hoist-dragging process. Owing to the pre-opened bolt holes on the steel battens, it is also convenient to install rigid roofing materials on the new structures, as shown in Figure 2b. Rigid roofing materials, such as light steel keels and glass plates, can be fixed onto steel battens just by high-strength bolts and nuts.

Binaural connections are adopted as the end nodes of the steel battens. One connection is composed of a backing plate, two ear plates and several stiffening ribs, as illustrated in Figure 2c. The end of a steel batten is welded to one side of the backing board, while the two ear plates are welded to the negative side of the backing board. Furthermore, to ensure local stability, the stiffener is welded to strengthen the connection between the backing board and the ear plates. The end of the steel batten is connected to the support by fixing the pin holes of the ear plates.

\subsection{Advantages of the SBRD}

Table 1 lists the similarities and differences between conventional cable domes and SBRDs. On the one hand, by building pretension forces in all cables and steel battens, the mechanical behaviors of an SBRD are similar to those of a conventional cable dome. On the other hand, by replacing flexible ridge cables with a semi-rigid steel batten, rigid materials, such as purlins and light frames, can be set on top of the main structure, and rigid roofing plates can be installed afterwards, which avoids the inconvenience of combining a conventional cable dome structure with a rigid roof. Moreover, the thickness of the steel battens is relatively smaller than the span of the overall structure. Before prestress is 
applied, the SBRD is weak in rigidity and flexible in overall shape, which makes it suitable for the implementation conditions of less-bracket consequent hoist-dragging construction and thus saves time and construction costs. Therefore, the SBRD is in line with the future development direction of large-span steel structures.

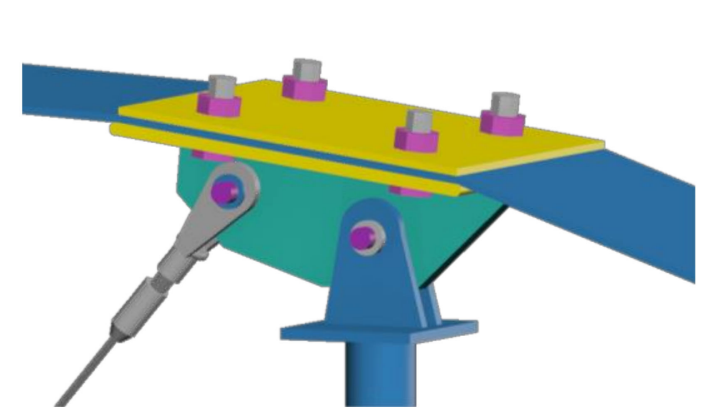

(a)

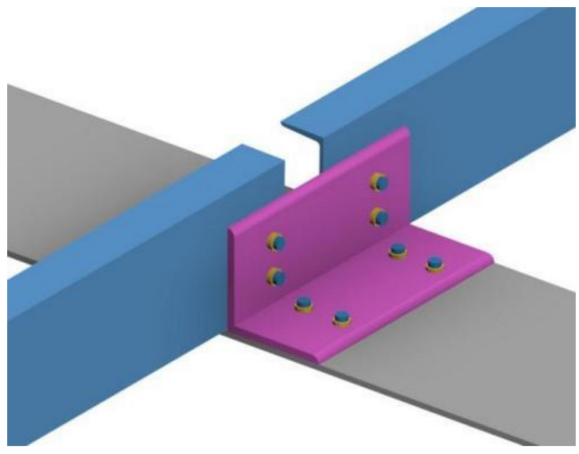

(b)

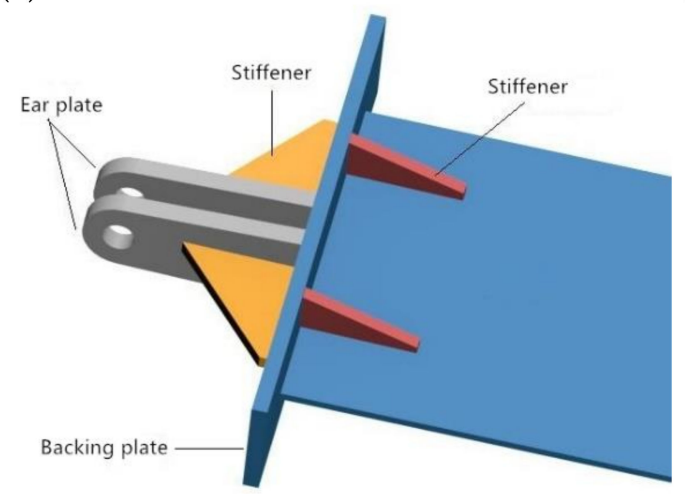

(c)

Figure 2. Schematic diagrams of the connecting joints. (a) Upper joint of the struts; (b) joint between the roof materials and steel battens; (c) end joint of the steel battens.

Table 1. Comparison of the conventional cable dome and SBRD in several aspects.

\begin{tabular}{ccc}
\hline Type & Conventional Cable Dome & SBRD \\
\hline $\begin{array}{c}\text { Construction } \\
\text { method } \\
\text { Roofing material }\end{array}$ & $\begin{array}{c}\text { Non-bracket or less-bracket hoist-dragging } \\
\text { construction and traditional methods } \\
\text { Only expensive flexible materials can be laid }\end{array}$ & $\begin{array}{c}\text { Non-bracket or less-bracket hoist-dragging } \\
\text { construction and traditional methods } \\
\text { Both expensive flexible materials and low-priced } \\
\text { rigid roofs can be laid }\end{array}$ \\
\hline $\begin{array}{c}\text { Prestress } \\
\text { establishment }\end{array}$ & Actively tension slanting cables or hoop cables & $\begin{array}{c}\text { Actively tension slanting cables or hoop cables, } \\
\text { and passively establish prestress in the steel } \\
\text { battens }\end{array}$ \\
\hline $\begin{array}{c}\text { Mechanical } \\
\text { behavior }\end{array}$ & $\begin{array}{c}\text { Struts and inner compression ring in } \\
\text { compression, others in tension }\end{array}$ & $\begin{array}{c}\text { Steel battens in tension and bending, struts and } \\
\text { inner compression ring in compression, others in } \\
\text { tension }\end{array}$ \\
\hline
\end{tabular}

\section{Design of the Test Model}

\subsection{Supporting System}

To study the construction response and static behaviors of the SBRD, a test model was designed with an $8 \mathrm{~m}$ diameter specimen. The specimen is mainly composed of three parts: the outer pressure ring beam, the upper tensile steel batten grid, and the bottom cable-strut system. The specimen is a centrally symmetrical structure, divided into 8 units in the circumferential direction and three pieces in the ring. The specimen consists of 
8 steel battens, 3 hoop cables, 24 slanting cables, 16 struts, an inner compression ring, and a supporting platform. The elevation view and actual photograph of the specimen are displayed in Figure 3a,b, respectively.

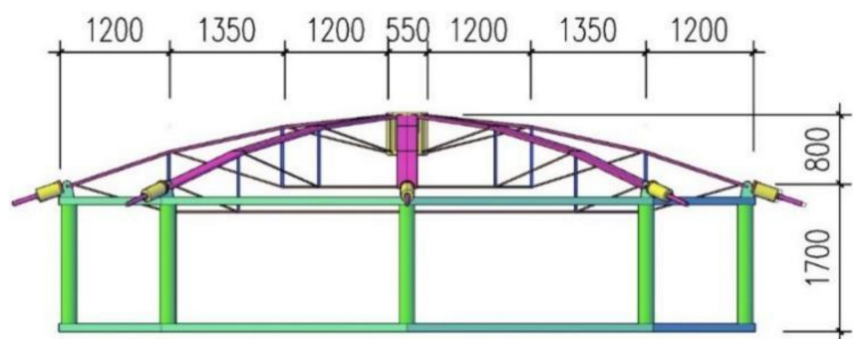

(a)

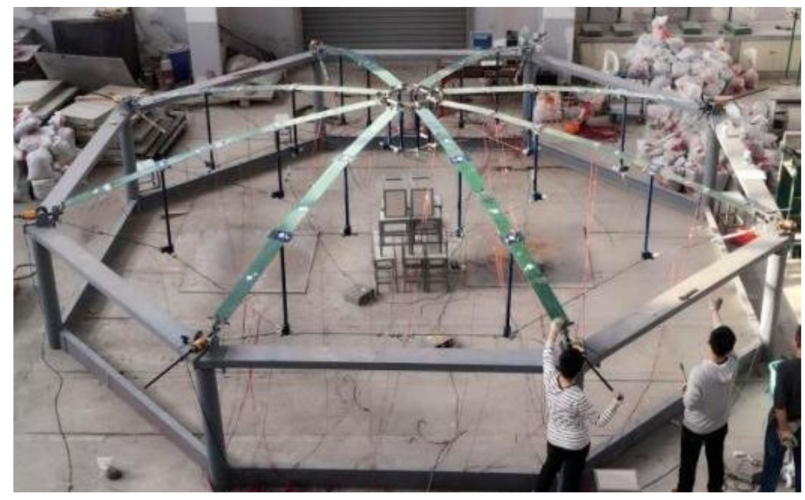

(b)

Figure 3. Test model of a levy hinged-beam cable dome. (a) Elevation view; (b) specimen photograph.

\subsection{Structural Members and Joints}

According to the preliminary calculation and test conditions, all of the cables used steel wire rope, with an adjustment length of $\pm 5 \mathrm{~mm}$ at both ends, while the steel battens used are Q345 strip-shaped steel plates, as shown in Figure 4. Steel tubes were welded with ear plates or ring beams to form the struts and inner compression ring, which are listed in Figure 5.

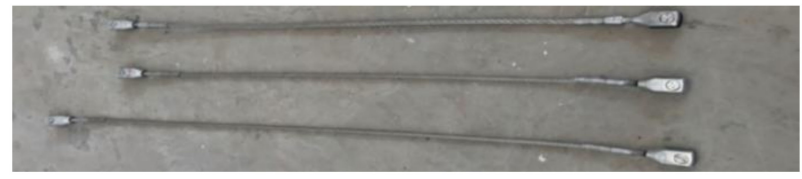

(a)

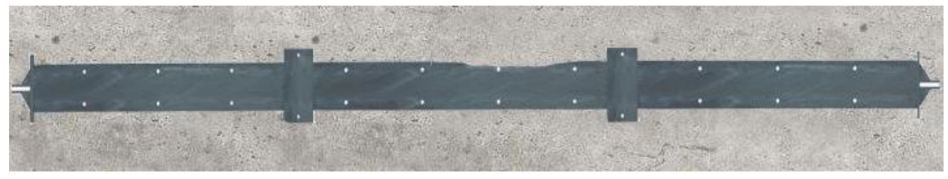

(b)

Figure 4. Photographs of the cables and steel battens. (a) Slanting cable and hoop cable; (b) steel batten.

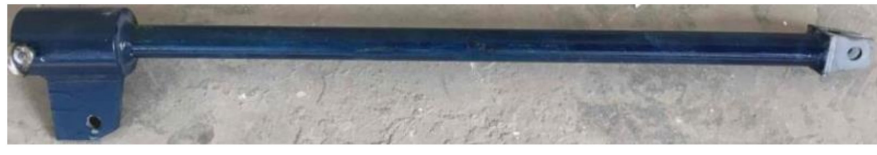

(a)

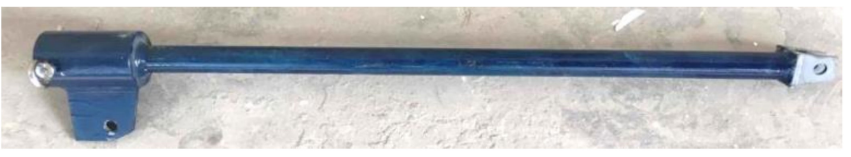

(b)

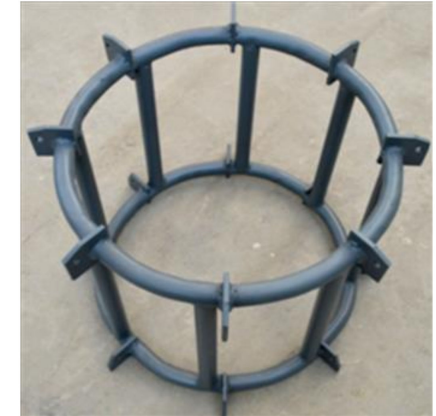

(c)

Figure 5. Photographs of the struts and inner compression ring. (a) Outer strut; (b) middle strut; (c) inner compression ring.

The connecting joints of the struts can be divided into two kinds, namely, the lower joints to connect the struts with adjacent slanting cables and hoop cables and the upper joints to connect the struts with steel battens via the connecting plate displayed in Figure 2a. An overview of the specimen parameters is summarized in Table 2. 
Table 2. Overview of specimen parameters.

\begin{tabular}{|c|c|c|c|c|}
\hline Component Name & Type & $\begin{array}{c}\text { Density } \\
\left(\times 10^{3} \mathrm{~kg} / \mathrm{m}^{3}\right)\end{array}$ & $\begin{array}{l}\text { Elastic Modulus } \\
\quad\left(\times 10^{11} \mathrm{~N} / \mathrm{m}^{2}\right)\end{array}$ & $\begin{array}{l}\text { Specification } \\
(\mathrm{mm})\end{array}$ \\
\hline Steel batten & Q345 & 7.85 & 2.06 & $150 \times 3$ \\
\hline Outer hoop cable & $1670 \mathrm{MPa}$ & 7.85 & 1.60 & $\Phi 7.7$ \\
\hline Inner hoop cable & $1670 \mathrm{MPa}$ & 7.85 & 1.60 & $\Phi 5$ \\
\hline Outer slanting cable & $1670 \mathrm{MPa}$ & 7.85 & 1.60 & $\Phi 5$ \\
\hline Middle slanting cable & $1670 \mathrm{MPa}$ & 7.85 & 1.60 & $\Phi 5$ \\
\hline Inner slanting cable & $1670 \mathrm{MPa}$ & 7.85 & 1.60 & $\Phi 5$ \\
\hline Outer strut & Q345 & 7.85 & 2.06 & $\Phi 34 \times 4$ \\
\hline Middle strut & Q345 & 7.85 & 2.06 & $\Phi 34 \times 4$ \\
\hline Inner compression ring & Q345 & 7.85 & 2.06 & $\Phi 34 \times 4$ \\
\hline
\end{tabular}

\subsection{Measurement System and Measuring Point Arrangement}

The stress and displacement of the specimen are the two main data points measured in this paper. Resistance strain gauges were used to measure the internal forces of the components, and strain gauges were attached to the front and back sides of each measuring component to eliminate errors caused by the eccentric forces and temperature during the test. The cable forces of all the cables were measured by a tensiometer, the nodal displacements are monitored by a total station, and a DH3816 static strain test system was adopted as the test data acquisition instrument. These devices are illustrated in Figure 6a-c.

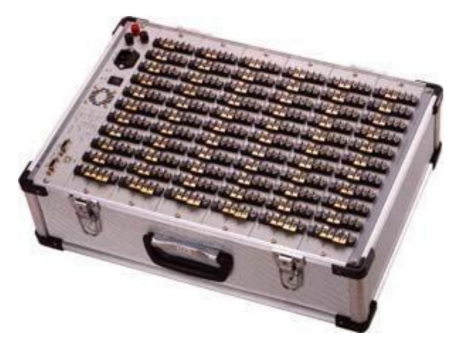

(a)

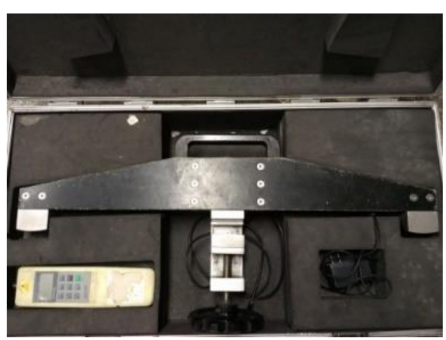

(b)

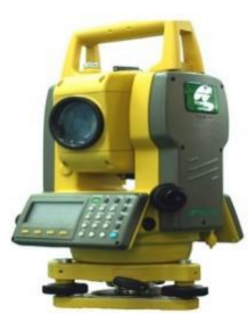

(c)

Figure 6. Test and measurement instrument. (a) DH3816 static strain test system. (b) Tensiometer. (c) Total station.

Strain measuring point: 24 points on the steel battens, of which eight are for the outer steel battens, eight are for the middle steel battens, and eight are for the inner steel battens.

Axial force measuring point: 24 points on the slanting cables, including eight on the outer slanting cables, eight on the middle slanting cables, and eight on the inner slanting cables. Eight points on the hoop cables, including four outer hoop cables and four inner hoop cables.

Displacement measuring point: 48 measuring points in total, which are eight points on the top of the outer struts, inner struts, and inner compression ring, and eight points on the mid-span of the outer steel battens, middle steel battens, and inner steel battens, respectively.

These measuring points are listed in Figure 7.

\subsection{Finite Element Model}

A finite element model was constructed in ANSYS software to simulate the axial force, nodal deformation, and member stress of the specimen.

Three-dimensional double-node spar element (LINK8), as shown in Figure 8a, was used to simulate the struts, which is subjected to uniaxial compression force or uniaxial tension force in one calculation. Three-dimensional double-node spar element (LINK10), listed in Figure 8b, was used to simulate the slanting cables and hoop cables, which is subjected to only uniaxial tension force. The three-dimensional double-node beam element 
(BEAM188), illustrated in Figure 8c, was used to simulate the steel battens and inner compression ring, which includes the stress stiffness and large deflection, and can simulate the mechanical properties of the steel battens and inner compression ring under loading. A single-node, concentrated mass element (MASS21), present in Figure 8d, was used to simulate the connecting joints between the cables and struts, which have three movement freedoms and three rotational freedoms.

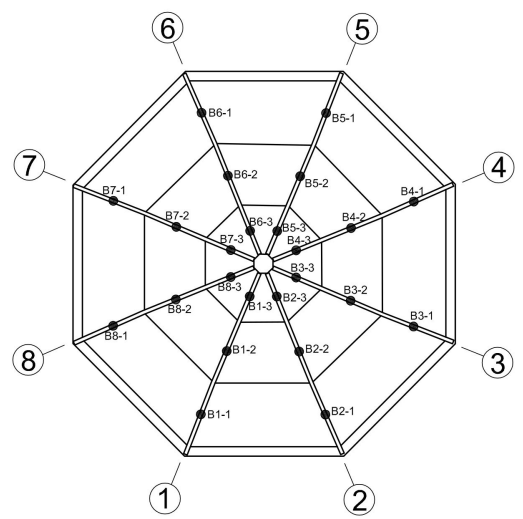

(a)

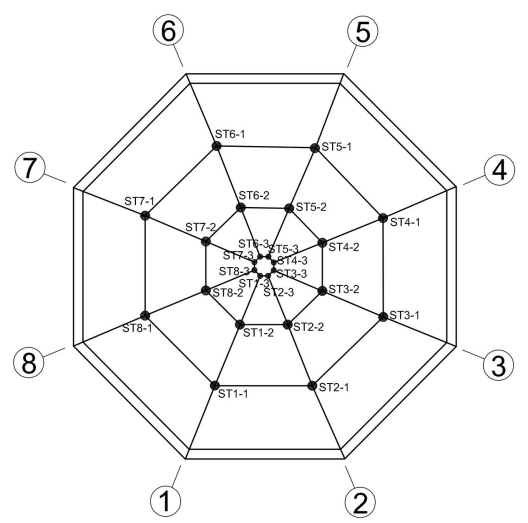

(d)

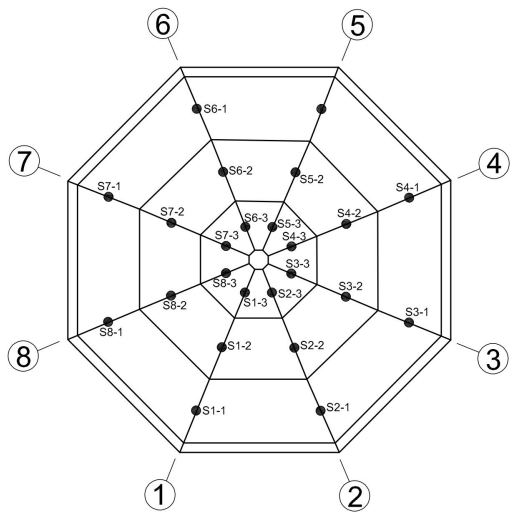

(b)

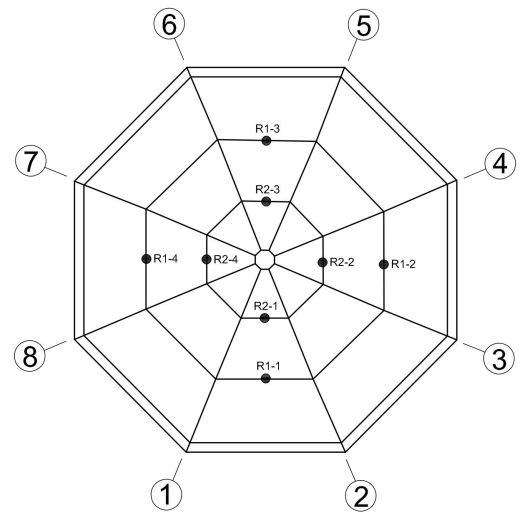

(c)

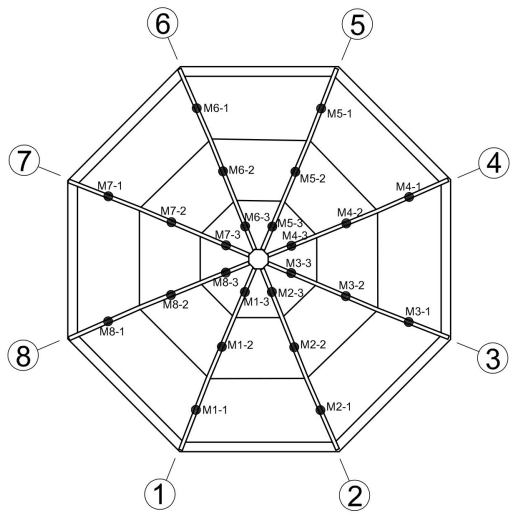

(e)

Figure 7. Layout of the measuring points of the specimen. (a) Strain points for the steel battens; (b) axial force points for the slanting cables; (c) axial force points for the hoop cables; (d) displacement points for the struts and the inner compression ring; (e) displacement points for the mid-span of the steel battens. (1)-8 mean the labels of eight bearing nodes.)

\subsection{Calculation of the Initial Prestress}

Unlike a traditional cable dome, the tensile steel strip cable dome provides no stiffness to bear external loads, so a prestress distribution must be found and built in the new structure. A simple force-finding method based on iteration is introduced as follows. A cable of length $L$ elongates under force $F$. The elongation $\Delta L$ can be calculated by Equation (1), and the strain $\varepsilon_{1}$ generated can be attained by Equation (2). If an initial strain $\varepsilon_{0}$ or equivalent temperature $\Delta T$, which is equal to $\varepsilon_{1}$, is applied on the cable, then the cable would recover its initial length. Using the basic principle to iterate, the initial configuration of the structures can be approached gradually. As a result, the prestress distribution could be known.

$$
\begin{aligned}
\Delta L & =\frac{F L}{E A} \\
\varepsilon_{l} & =\frac{F}{E A}
\end{aligned}
$$




$$
\Delta T=\frac{\varepsilon_{0}}{\alpha}
$$

where $F$ is the tensile force of a cable, $E$ is the elastic modulus of a cable, $A$ is the area of a cable, $\Delta T$ is the equivalent temperature difference of a cable, and $\alpha$ is the temperature expansion coefficient of a cable. In this study, $\alpha=1.2 \times 10^{-5}$.

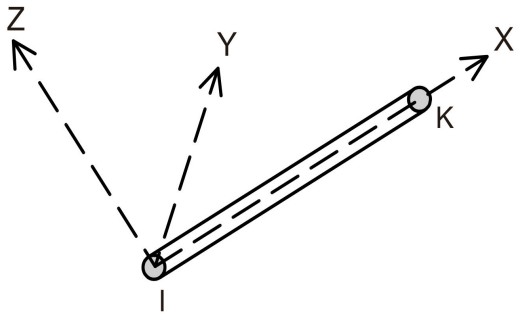

(a)

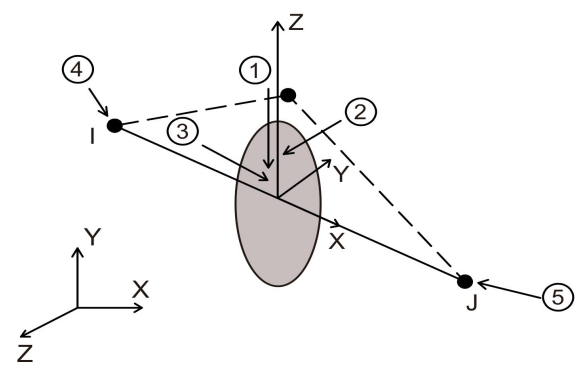

(c)

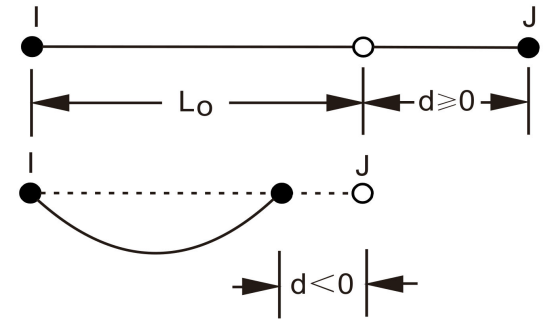

(b)

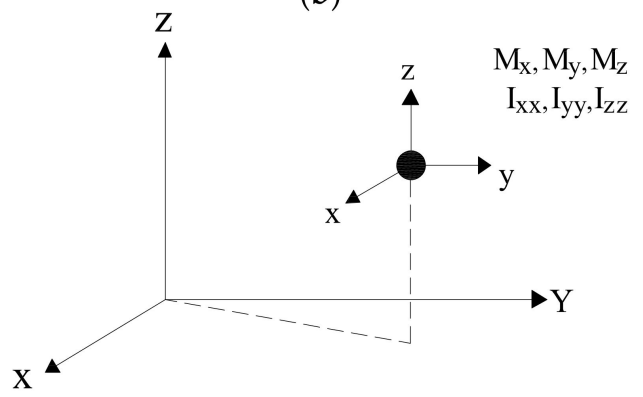

(d)

Figure 8. Element types used in the finite element simulation. (a) 3D two-node tension-compression element, LINK8; (b) 3D two-node cable element, LINK10; (c) 3D two-node beam element, BEAM188; (d) single-node, concentrated mass element, MASS21.

According to the mechanical properties of the specimen under the combination of self-weight and prestress, the axial forces of the members are illustrated in Table 3.

Table 3. Component specifications and initial prestress.

\begin{tabular}{ccc}
\hline Component No. & Specification & Initial Pretension Force/N \\
\hline Outer steel batten & Beam188 & 14,418 \\
Middle steel batten & Beam188 & 9496 \\
Inner steel batten & Beam188 & 7376 \\
Outer hoop cable & Link8 & 12,861 \\
Inner hoop cable & Link8 & 5672 \\
Outer slanting cable & Link8 & 10,994 \\
Middle slanting cable & Link8 & 4842 \\
Inner slanting cable & Link8 & 2069 \\
Outer strut & Link8 & - \\
Middle strut & Link8 & - \\
Inner compression ring & Beam188 & - \\
Connecting joint & Mass21 & \\
\hline
\end{tabular}

\section{Test of the Construction Process}

\subsection{The ' $\omega$ ' Shaped Less-Bracket Consequent Hoist-Dragging System for the SBRD}

Before the prestress is applied, the SBRD is in a flexible state with several variable shapes. Therefore, it is beneficial for this structure to adopt the less-bracket consequent hoist-dragging method to implement the construction. The ' $\omega$ ' shaped less-bracket consequent hoist-dragging construction technology is an efficient method that possesses the characteristics of a less-bracket and small hoist force. During the construction process, the upper steel batten grid and the bottom cable-strut system experience the initial stressfree flexible state, low-stress sag state, and high-stress stiffening state, and finally reach 
the forming state. The construction process consists of three main stages: low-altitude assembly and connection stage, aerial hoist-dragging stage, and high-altitude forming and tensioning stage. The details are as follows.

(1) First, the outer compression beam, hoisting cables, steel battens, inner compression ring, hoisting cables, and dragging cables are assembled, and then the cables and struts are installed under the steel battens. After that, the ends of each component are hinged.

(2) The outer compression beam is taken as the support to alternately lift and tract the steel batten grid. In each operation cycle, the lifting work should be taken before the hoist to maintain the ' $\omega$ ' shape of the entire structure and to ensure the global stability of the structure during this process.

(3) As the structure rises, the steel batten grid is gradually stretched until the end joints of the outer steel battens are connected with the outer compression beam.

(4) The hoisting cables and dragging cables are removed. The outermost slanting cables are synchronously tensioned to build the prestress of the entire structure, and then a spatial structure with a certain rigidity that is able to withstand external loads is formed.

(5) Finally, the total roof is divided into several units, according to the plane size, and then the rigid roofing plates are laid.

The detailed stages are illustrated in Figure 9.

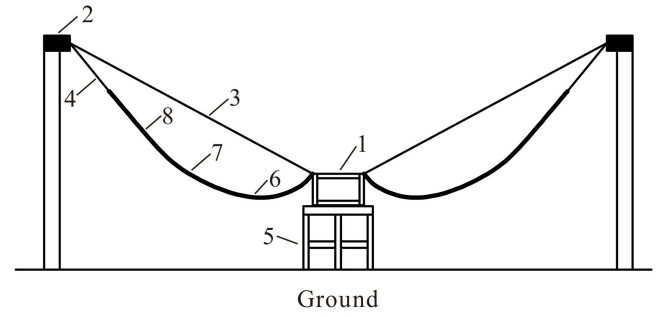

(a)

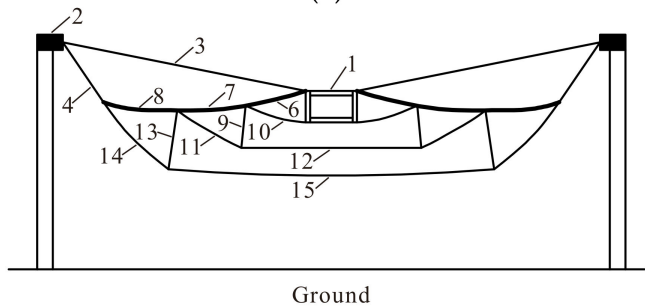

(c)

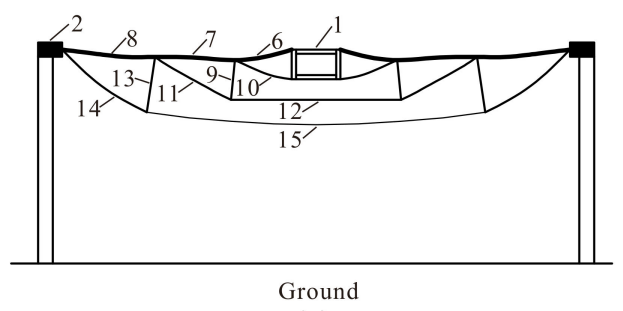

(e)

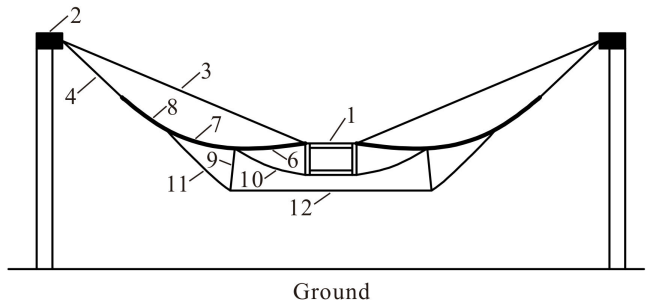

(b)

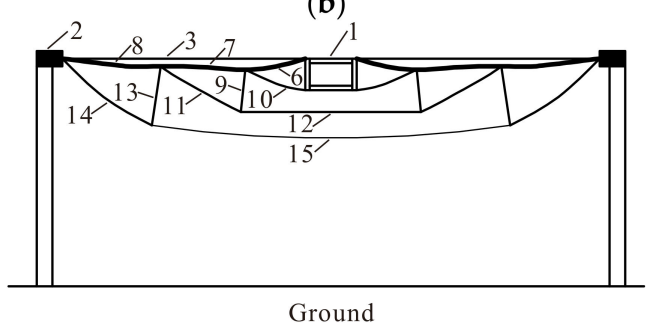

(d)

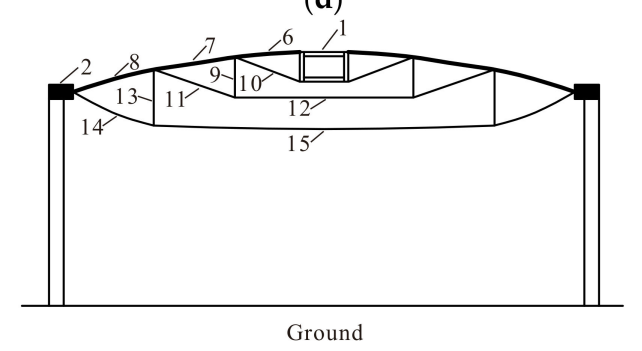

(f)

Figure 9. Detailed process of the $\omega$ shaped less-bracket consequent hoist-dragging system. (a) Assemble the outer compression beam, hoisting cables, steel battens, inner compression ring, and tool cables; (b) install the cables and struts under the steel battens, then hinge the ends of each component; (c) alternately lift and tract the steel batten grid; (d) connect the ends of outer steel battens with outer compression beam; (e) remove tool cables, tension outer slanting cables to establish prestress; (f) lay rigid roofing plates. (1: inner compression ring; 2: outer compression beam; 3: hoisting cable; 4: dragging cable; 5: central bracket; 6: inner steel batten; 7: middle steel batten; 8: outer steel batten; 9: inner strut; 10: inner slanting cable; 11: middle slanting cable; 12: inner hoop cable; 13: outer strut; 14: outer slanting cable; 15: outer hoop cable). 
In the SBRD specimen, four hoisters were symmetrically arranged in the middle of the eight ring beams around the periphery. Each hoister was welded to the outer compression beam at one end, and the other end was connected to the inner compression ring through a wire rope to simulate a hoisting cable, as shown in Figure 10a. Each outermost end of the outer steel batten was connected with a gusset plate through a bolt, and each outer slanting cable was connected with a gusset plate through an adjustable stainless steel 304 basket screw. An adjustable screw, passing through the center of the gusset plate and the support sleeve, was provided at each support node to simulate dragging cables, as shown in Figure 10b. The details of the adjustable stainless steel 304 basket screw are presented in Figure 10c.

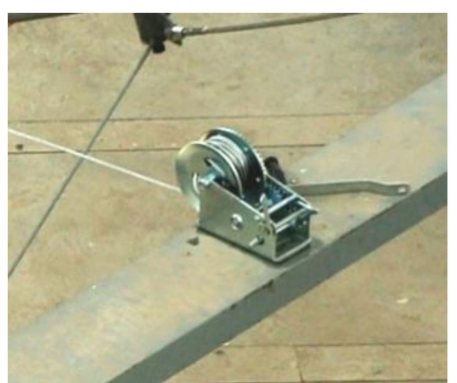

(a)

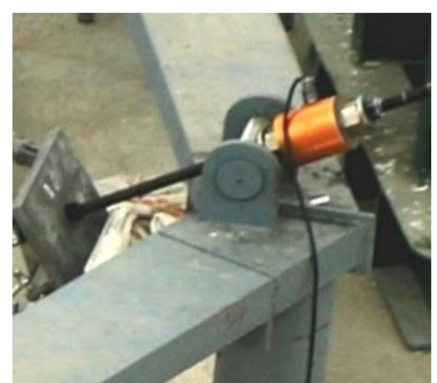

(b)

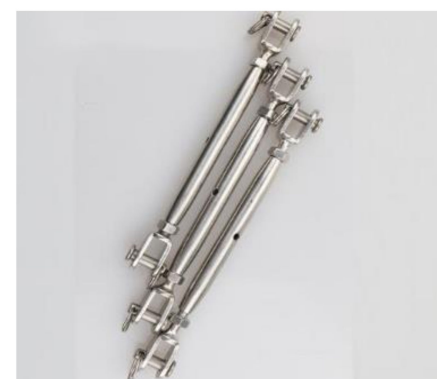

(c)

Figure 10. Toolings of the $\omega$ shaped less-bracket consequent hoist-dragging system. (a) Hoister; (b) gusset plate; (c) adjustable stainless steel 304 basket screws.

For the specimen adopted in this study, the $\omega$ shaped less-bracket consequent hoistdragging system was performed as follows, and the analysis steps are listed in Table 4.

Table 4. Analysis steps of the construction process.

\begin{tabular}{ccccc}
\hline \multirow{2}{*}{ Step } & & \multicolumn{3}{c}{ Original Length (mm) } \\
\cline { 3 - 5 } & & Hoisting Cables & Dragging Cables & Outer Slanting Cables \\
\hline Initial stage & 0 & 4560 & 720 & +120 \\
& 1 & 4380 & 570 & +120 \\
Hoist-dragging & 2 & 4200 & 420 & +120 \\
& 3 & 4020 & 270 & +120 \\
& 4 & 3840 & 120 & +120 \\
Demolish the hoisting cables & 5 & 3750 & 50 & +120 \\
and dragging cables & 6 & 3725 & 0 & +120 \\
\hline & & - & - & +120 \\
Tension the outer slanting & 10 & - & - & +100 \\
cables & 11 & - & - & +80 \\
& 12 & - & - & +60 \\
\end{tabular}

\section{A. Preparation and assembly}

The initial lengths of all the components were determined and the initial strain values of the components were recorded. Compression sensors were set at each support, and strain gauges were attached to the corresponding components. To facilitate the installation of components, the inner compression ring was placed at a height of $1.2 \mathrm{~m}$ in the center of the site, and then the steel battens, struts, and cables were installed from the inside to the outside, as shown in Figure 11a. The lengths of the hoop cables were strictly controlled, 
and the clamps of the hoop cables were tightened to prevent slipping, as displayed in Figure $11 \mathrm{~b}$. The strain values of the components and the altitude of each circle node from the ground were recorded.

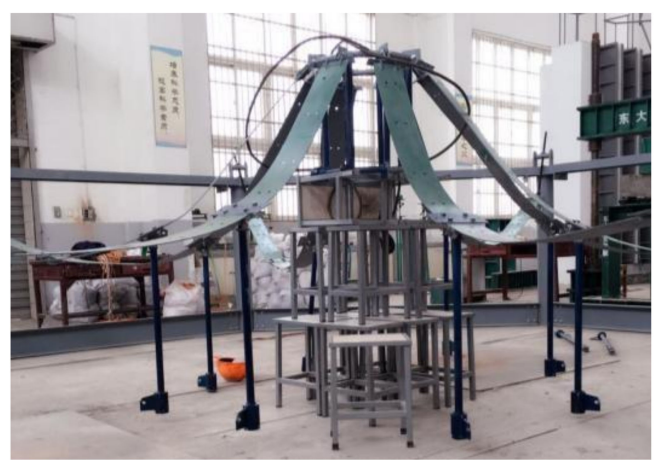

(a)

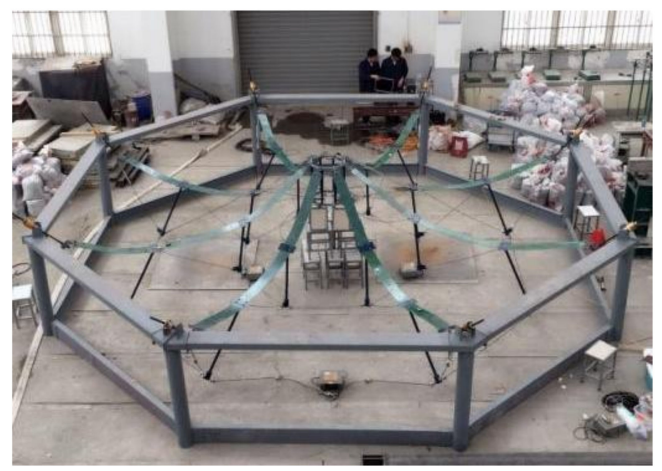

(c)

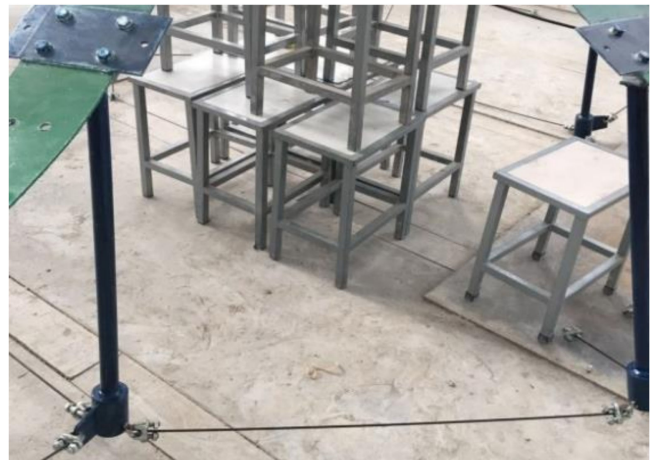

(b)

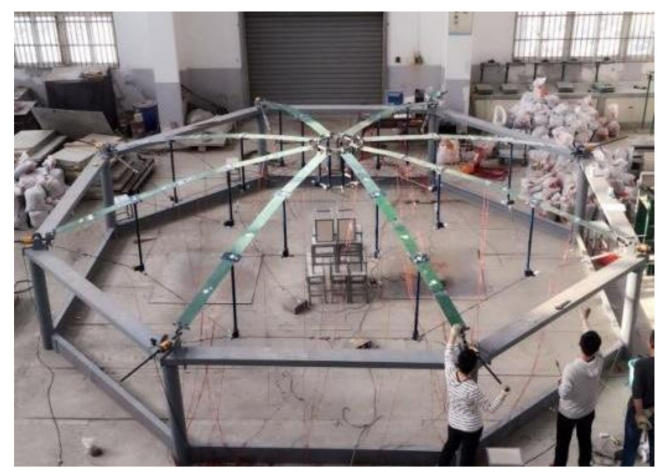

(d)

Figure 11. Paragraphs of the actual construction process. (a) Assemble the steel battens and struts; (b) install the slanting cables and hoop cables; (c) implement the hoist-dragging process; (d) adjust the lengths of the basket screws and mold the entire structure.

\section{B. Hoisting and dragging}

By tightening the nut of the adjustable screw, the length of the screw was adjusted, and outer steel battens and the outer slanting cables were hauled. Meanwhile, the inner compression ring was dragged by the four hoisters. The adjustable screws were shortened in six steps, and the adjustment lengths are $-150 \mathrm{~mm},-150 \mathrm{~mm},-150 \mathrm{~mm}$, $-150 \mathrm{~mm},-70 \mathrm{~mm}$, and $-50 \mathrm{~mm}$, while the adjustment lengths of the traction wire ropes are $-180 \mathrm{~mm},-180 \mathrm{~mm},-180 \mathrm{~mm},-180 \mathrm{~mm}, 90 \mathrm{~mm}$, and $-25 \mathrm{~mm}$, respectively. After each step, the strain value of each measured member and the ground clearance of each measured node were recorded. This process is listed in Figure 11c.

\section{Tensioning and molding}

The basket screws were adjusted six times to build the prestress of the overall structure, and the adjustment lengths are $-20 \mathrm{~mm},-20 \mathrm{~mm},-20 \mathrm{~mm},-20 \mathrm{~mm},-20 \mathrm{~mm}$, and $-20 \mathrm{~mm}$, as shown in Figure 11d. After each step, the strain value of each measured member and the ground clearance of each measured node were recorded as well.

\subsection{Results for ' $\omega$ ' Shaped Less-Bracket Consequent Hoist-Dragging Construction}

The static configurations of several construction steps are illustrated in Figure 12. The internal forces of the auxiliary cables, slanting cables, and hoop cables are illustrated in Figures 13-15, respectively. Figure 16 lists the average vertical difference of the top nodes of the struts and inner compression ring, while Figure 17 lists the average mid-span displacement of the steel battens. 


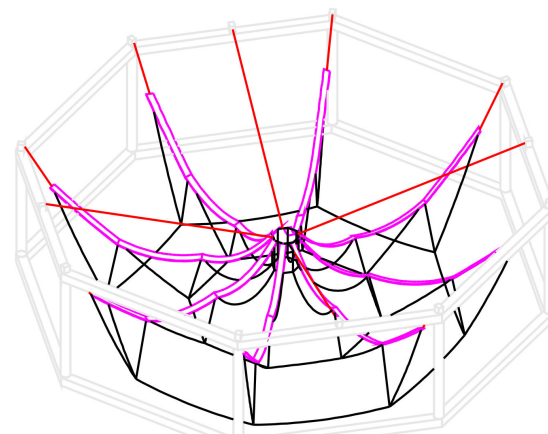

(a)

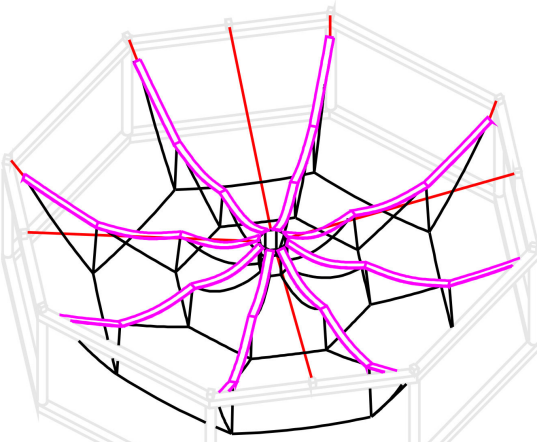

(c)

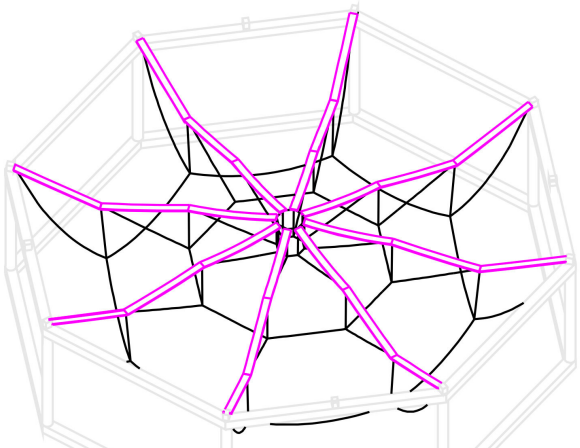

(e)

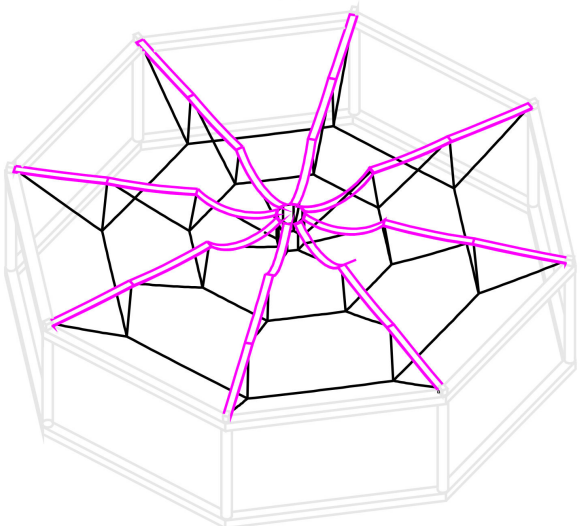

(g)

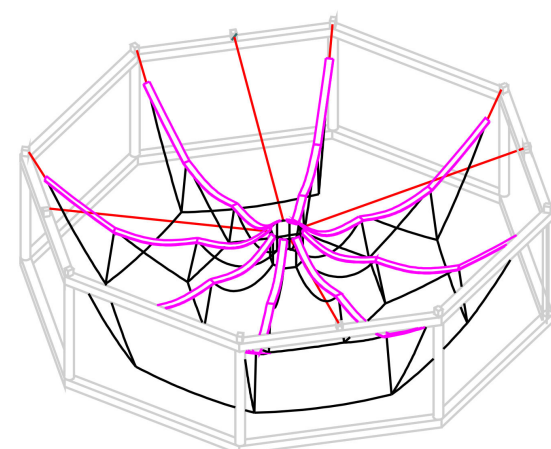

(b)

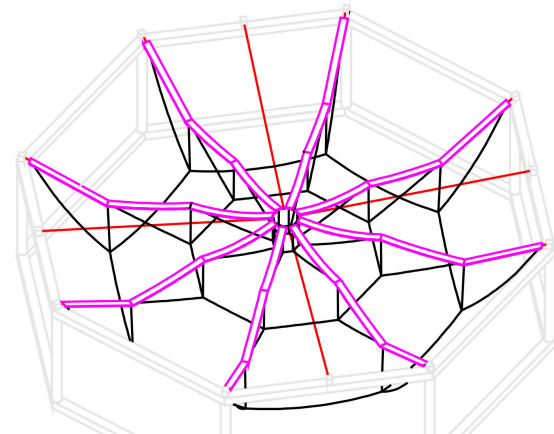

(d)

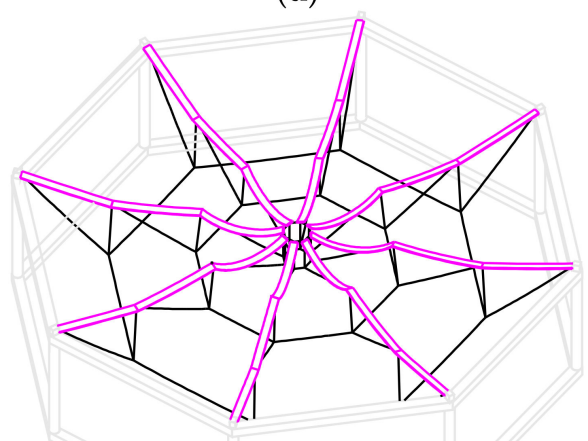

(f)

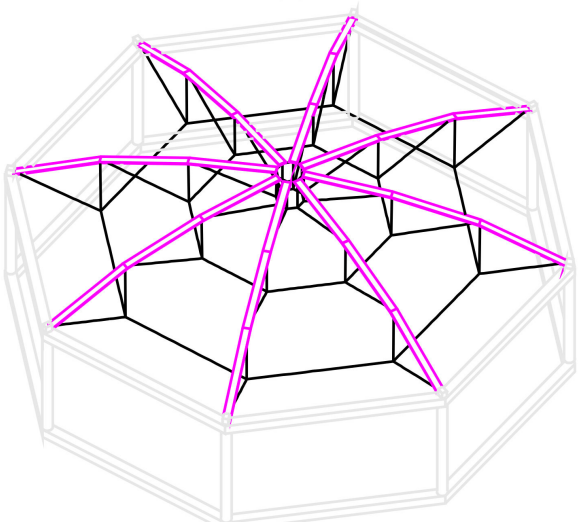

(h)

Figure 12. Three-dimensional graphs of the SBRD model during constructional simulation. (a) Step 0; (b) Step 2; (c) Step 4; (d) Step 6; (e) Step 7; (f) Step 9; (g) Step 11; (h) Step 13. 


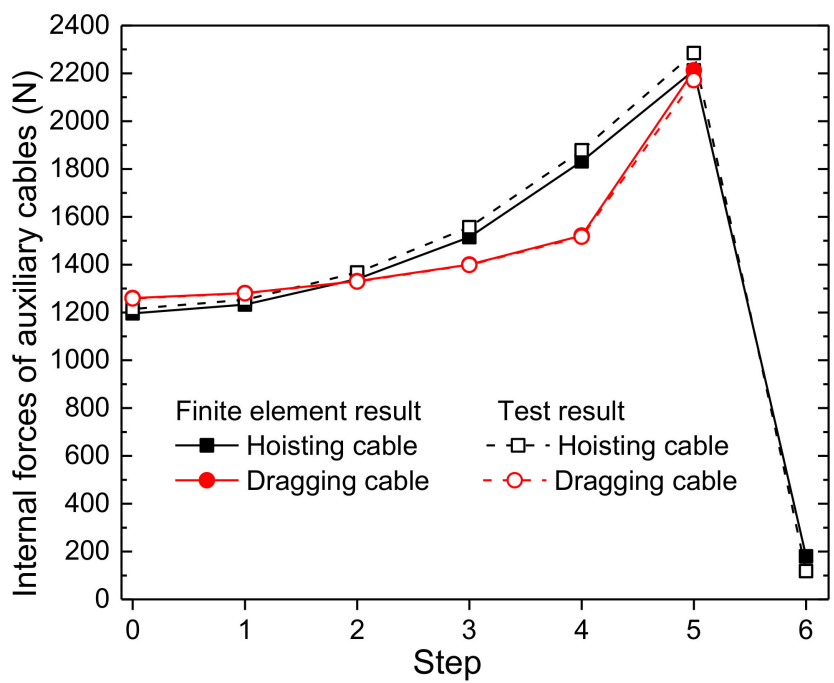

Figure 13. Internal forces of auxiliary cables during construction.

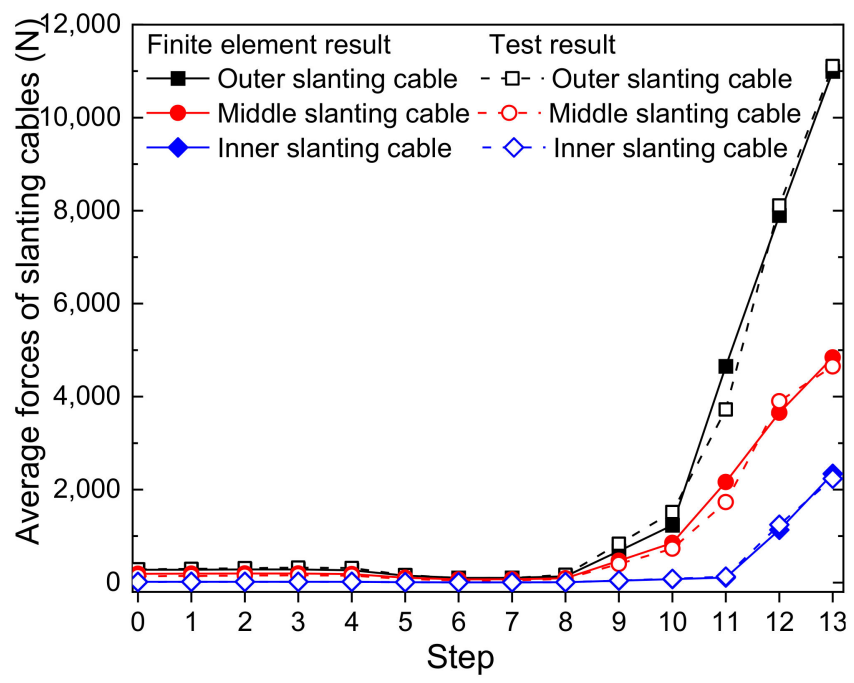

Figure 14. Axial forces of slanting cables during construction.

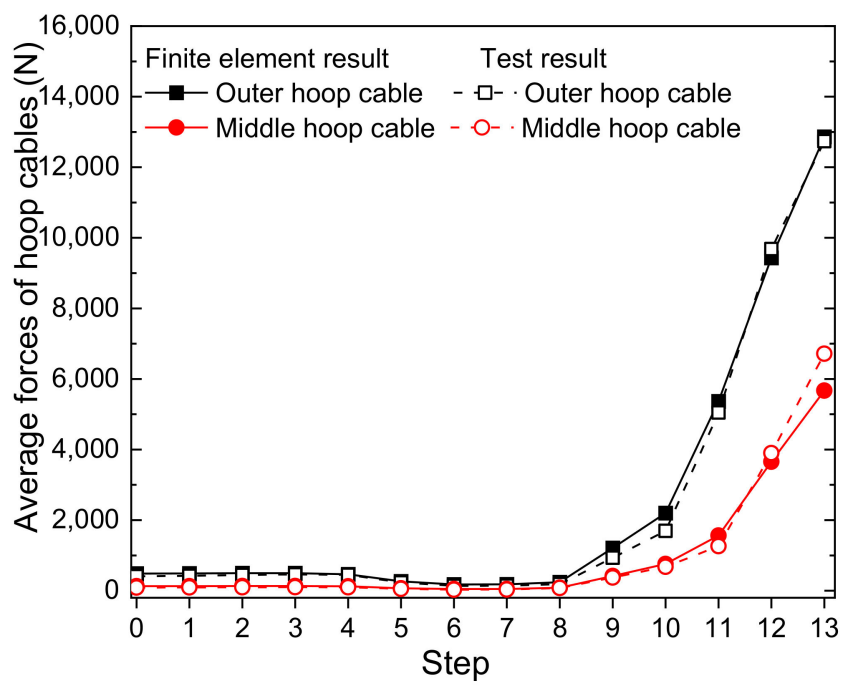

Figure 15. Axial forces of the hoop cables during construction. 


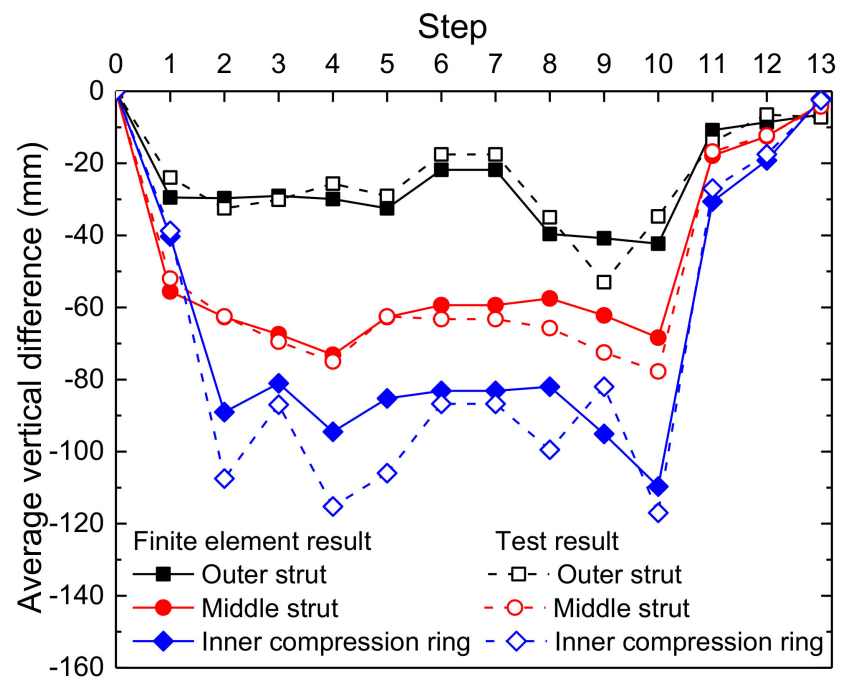

Figure 16. Average vertical difference of the top nodes of the struts and inner compression ring.

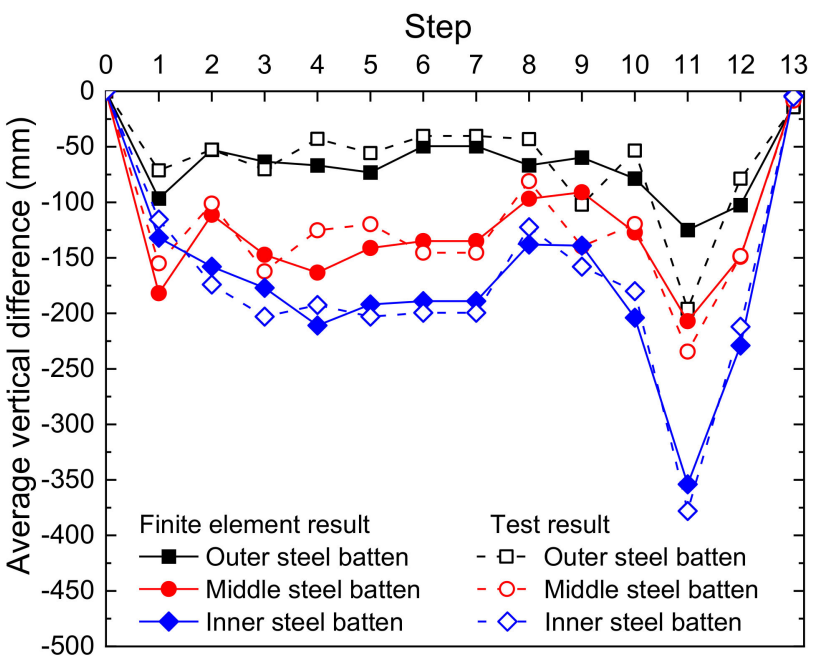

Figure 17. Average mid-span displacement of the different segments of the steel battens.

The results depict that in the early steps of hoisting and dragging, the structure establishes the prestress, accumulates stiffness, and finds its own internal force balance, while the entire structure keeps the shape of " $\omega$ " so that all the cables and struts remain suspended under the steel battens to guarantee the stability of the overall configuration. During this process, the internal forces of all the components are small, which magnifies the production deviation of the specimen and the measurement deviation of the testing instruments and thus leads to large deviations between the test values and finite element values. The maximum deviation of the vertical displacement is $-117 \mathrm{~mm}$, which occurs at the top of the inner compression ring. As the internal force of the component increases in the following steps, the effect of these two deviations decreases, and the configuration of the entire structure changes from a " $\omega$ " shape with both ends and midpoint exhibiting a concave structure to an " $\mathrm{m}$ " shape with both ends and midpoint exhibiting a convex structure. In the last stage of tensioning, small variations occur in the vertical displacements of the struts, while the forces of the steel battens and cables increase rapidly, the mid-span displacements of the steel battens gradually decrease, the overall prestress of the structure is established, and the entire structure varies from the initial relaxed state to the molding state. After the tensioning is completed, the largest difference between the test values and finite element values is within $20 \%$. 
Figures 18 and 19 illustrate the tensile stresses and bending stresses of the steel battens, respectively.

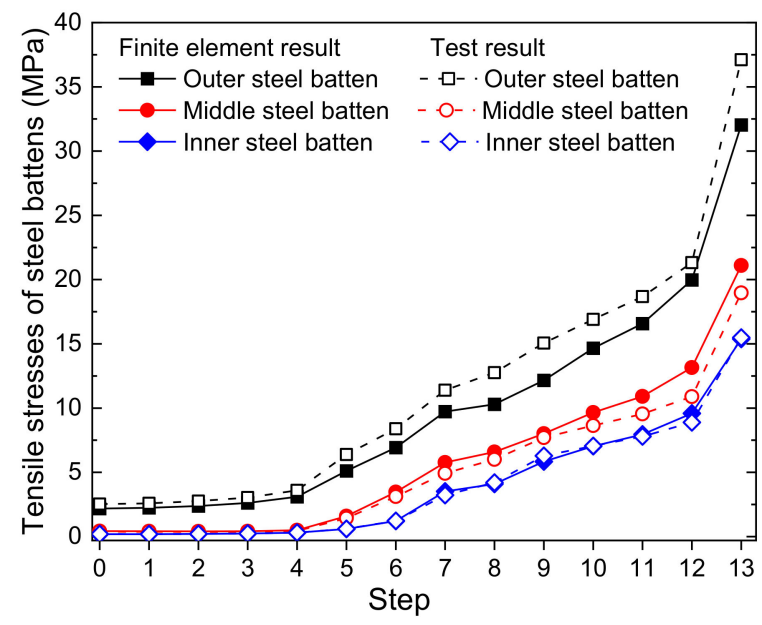

Figure 18. Tensile stresses of the steel battens.

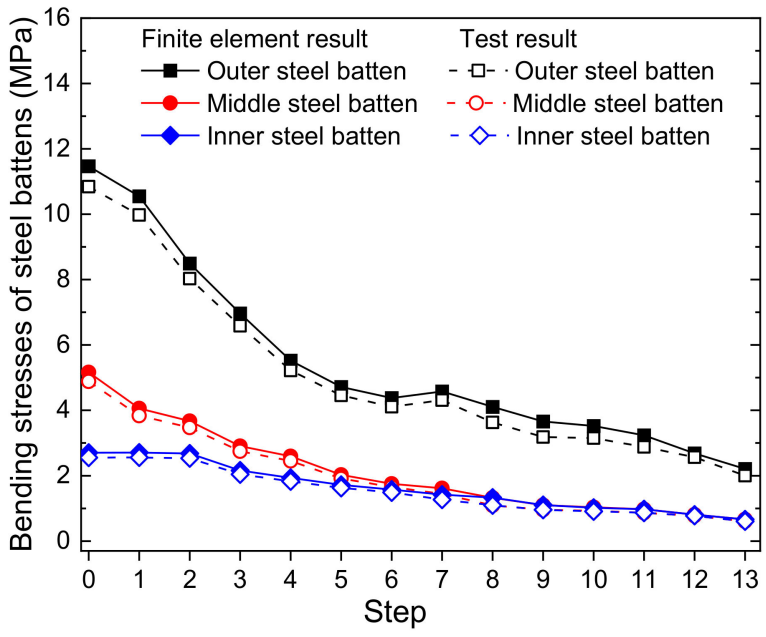

Figure 19. Bending stresses of the steel battens.

During the initial hoisting and dragging steps, small increasing axial forces and large mutative deformations occur in the steel battens, which leads to the slowly growing tensile stresses and the drastically decreasing bending stresses of all the steel battens. However, after demolishing the auxiliary cables in Step 7, part of the self-weight born by hoisting cables and dragging cables is transferred to the steel battens, which led to a remarkable increase in the tensile stresses and bending stresses. In general, the experimental results of the internal forces and deformations of all the components are basically consistent with the finite element results throughout the construction process, indicating that the finite element model reflects the structural response of the SBRD specimen.

\section{Test of Static Loading Performance}

\subsection{Summary of the Static Loading Test}

To study the structural response of the SBRD under a complex static load, tests of symmetric uniform loading and asymmetric uniform loading were implemented, as shown in Figure 20a,b. The schematic diagrams of these two loading areas were displayed in Figure 21a,b. A uniform load was added by hanging sandbags on the bottom side of all steel battens in the four steps, and then the uniform load was removed in the four steps as well. The added loading values for each segment of the steel battens are 
displayed in Tables 5 and 6 . From actual engineering experience, the weight of a rigid glass roofing system is approximately $0.7 \mathrm{kN} / \mathrm{m}^{2}$. In the following two tables, the values of the first loading steps were performed to simulate this load, while the last loading steps were conducted to investigate the static responses of the SBRD under different live load conditions.

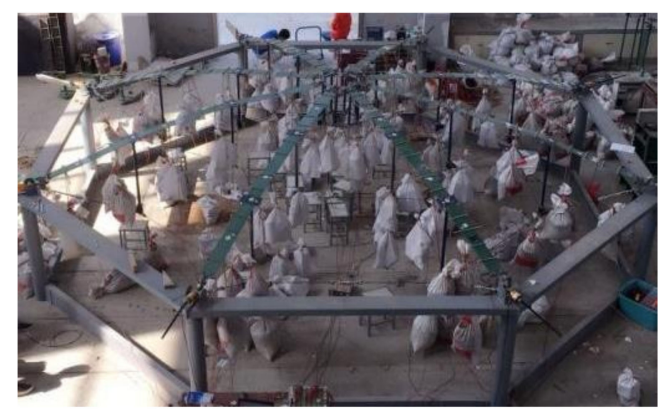

(a)

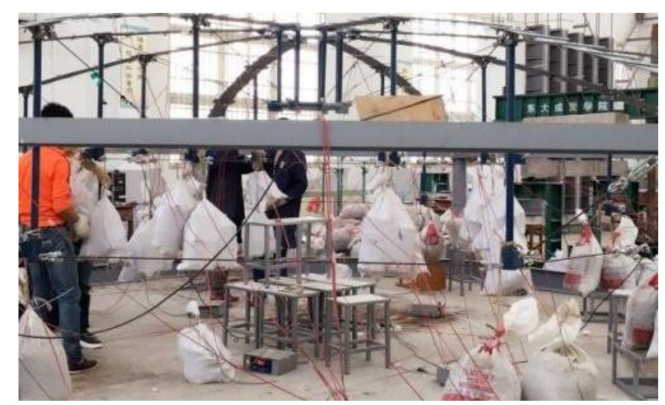

(b)

Figure 20. Photographs of the static loading test. (a) Symmetric uniform; (b) asymmetric uniform.

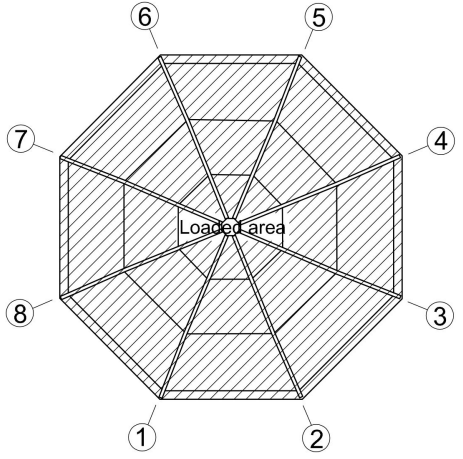

(a)

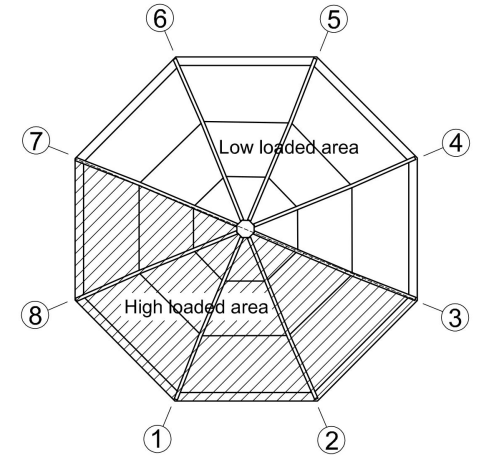

(b)

Figure 21. Schematic diagrams of the loading area. (a) Symmetric uniform; (b) asymmetric uniform.

Table 5. Added loading values for the full-span test (unit: N).

\begin{tabular}{cccc}
\hline Loading Step & Outer Steel Batten & Middle Steel Batten & Inner Steel Batten \\
\hline 1 & 740 & 470 & 200 \\
2 & 1480 & 940 & 400 \\
3 & 2220 & 1410 & 600 \\
4 & 2960 & 1880 & 800 \\
\hline
\end{tabular}

Table 6. Added loading values for the half-span test (unit: N).

\begin{tabular}{ccccc}
\hline Loading Step & Region & Outer Steel Batten & Middle Steel Batten & Inner Steel Batten \\
\hline \multirow{2}{*}{1} & High loaded area & 740 & 470 & 200 \\
& Low loaded area & 740 & 470 & 200 \\
2 & High loaded area & 1480 & 940 & 400 \\
& Low loaded area & 740 & 1410 & 600 \\
\multirow{2}{*}{3} & High loaded area & 2220 & 470 & 200 \\
& Low loaded area & 740 & 1880 & 800 \\
& High loaded area & 2960 & 470 & 200 \\
\hline
\end{tabular}




\subsection{Results of Symmetric Uniform Loading}

The internal forces of the components obtained by the test and finite element simulation under a symmetric uniform load are illustrated in Figure 22, the average stresses of the steel battens are presented in Figure 23, and the displacement results are shown in Figure 24.

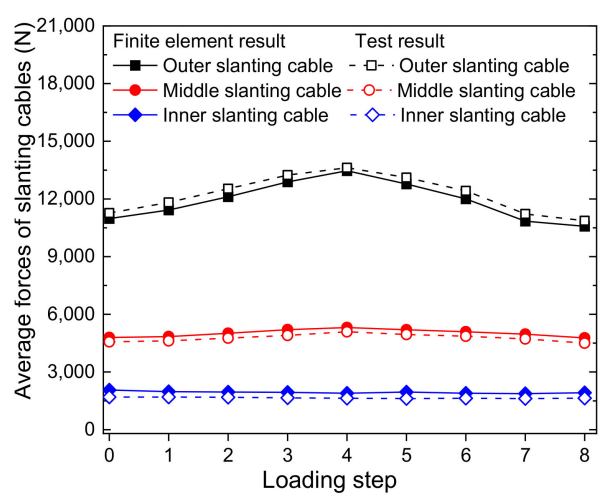

(a)

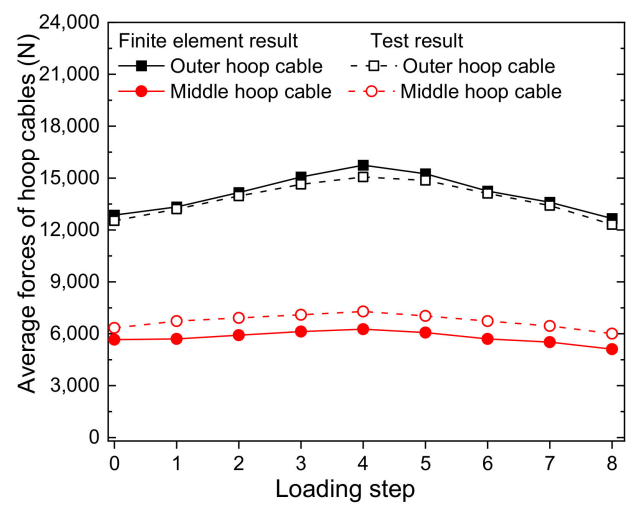

(b)

Figure 22. Internal forces of the components during symmetric uniform loading. (a) Slanting cables; (b) hoop cables.

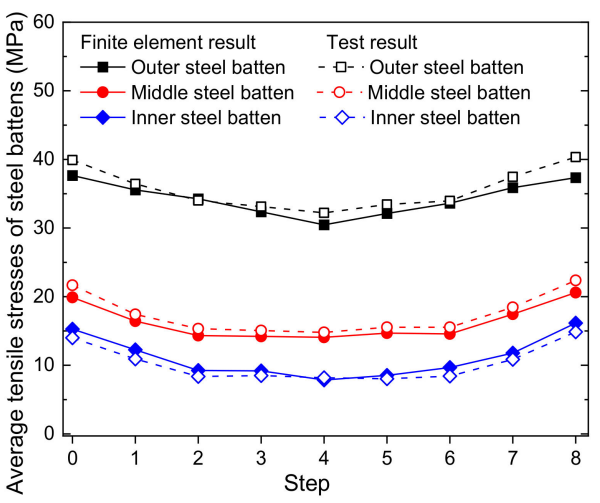

(a)

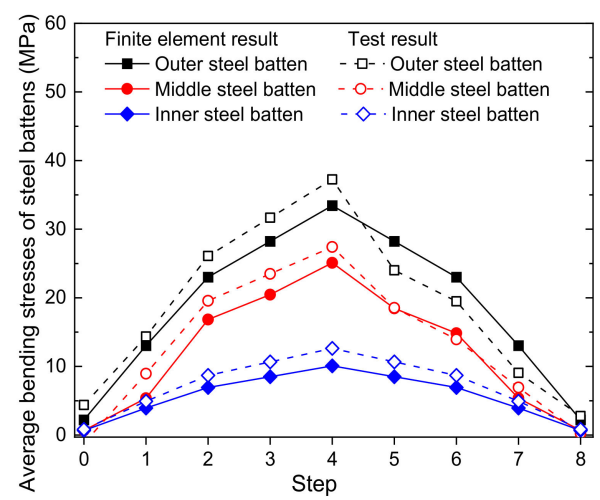

(b)

Figure 23. Average stresses of the steel battens during symmetric uniform loading. (a) Tensile stresses; (b) bending stresses.

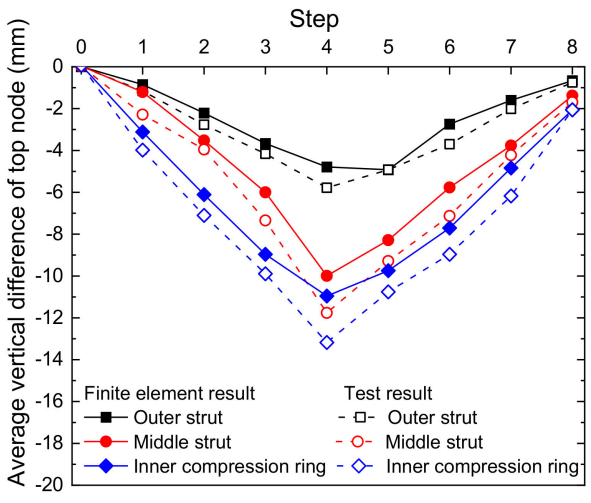

(a)

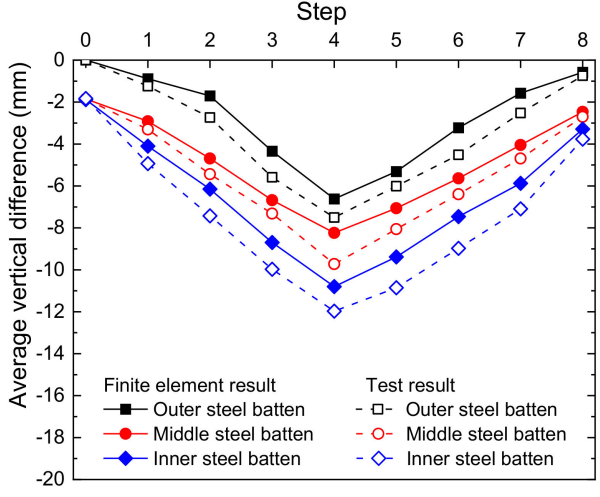

(b)

Figure 24. Average differences of the measuring nodes during symmetric uniform loading. (a) Top nodes of the struts; (b) segments of the steel battens. 
Under the symmetric uniform load, the measured internal forces of all the cables are basically consistent with the finite element values, and the maximum deviation is within $16.1 \%$. Particularly, the difference between the measured values and theoretical values of the inner cables (i.e., inner slanting cables and inner hoop cables) are comparatively large, which is mainly due to the unevenly distributed prestress level of the inner hoop of the specimen, the relatively smaller forces of the axial cables, and the relatively larger influence caused by the manufacturing and measurement errors. With increasing symmetric uniform load, the tensile stresses of the steel battens and the internal forces of all the cables gradually decline, while the bending stresses of the steel battens increase. The total stresses of the steel battens do not exceed their yield strength; that is, the steel battens are in the elastic stage during the loading steps. After unloading, stress relaxation occurs in several components; therefore, the axial force of all the cables and the tensile stresses of the steel battens are somewhat lower than the initial ones.

Moreover, the load-displacement curve demonstrates a good linear law for both the experimental and finite element results. The maximum vertical displacement occurs in the inner compression ring. The measured value is $-13.18 \mathrm{~mm}$, and its finite element value is $-10.96 \mathrm{~mm}$.

\subsection{Results of Asymmetric Uniform Loading}

After symmetric uniform loading, all the components were still in elastic state. Then, the sandbags were removed from the steel battens, while the forces of cables and struts were modulated afterwards until the entire structure basically recovers the initial prestress state before the symmetric uniform loading test. The internal forces of the cables, the stresses of the steel battens, and the displacement variations in the asymmetric uniform loading test are displayed in Figures 25-27, respectively, where "high loaded area" represents the components in the shaded region of Figure $21 \mathrm{~b}$ with the relatively heavier external load of Table 6, and "low loaded area" represents the components in the unshaded region of Figure $21 \mathrm{~b}$ with the relatively lower external load of Table 6.

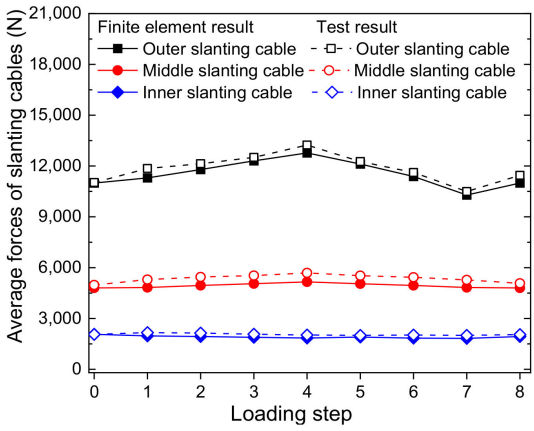

(a)

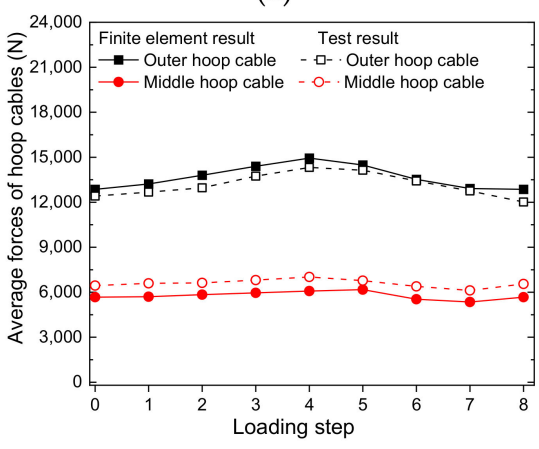

(c)

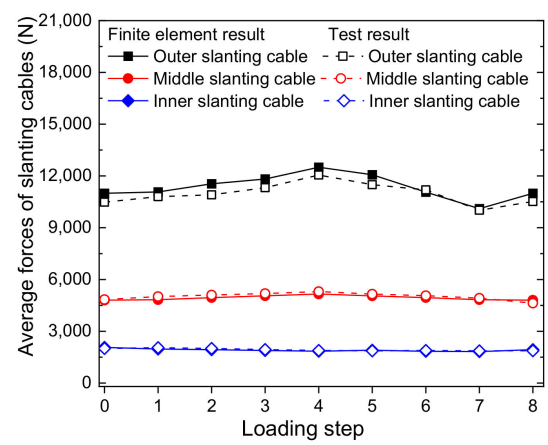

(b)

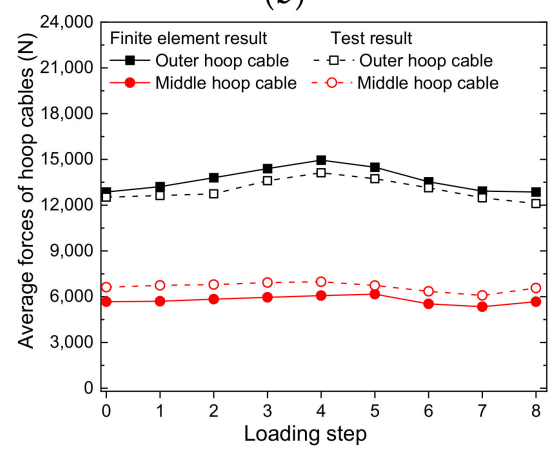

(d)

Figure 25. Internal forces of the cables during asymmetric uniform loading. (a) Slanting cables in the high loaded area; (b) slanting cables in the low loaded area; (c) hoop cables in the high loaded area; (d) hoop cables in the low loaded area. 


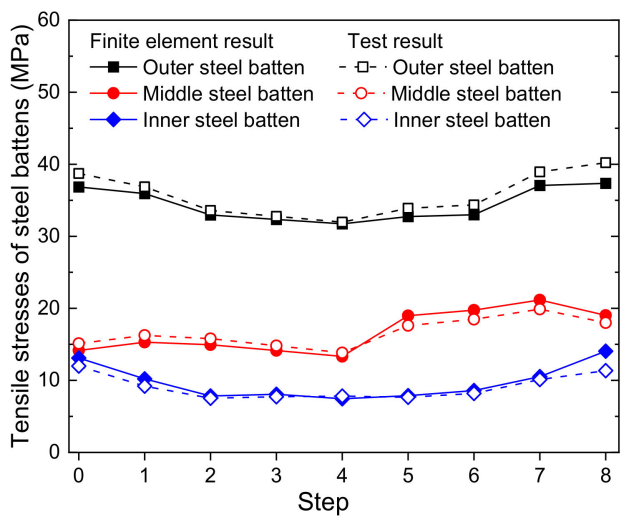

(a)

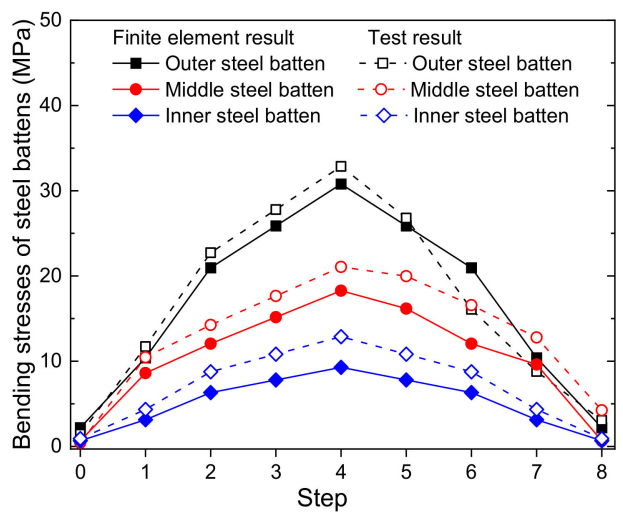

(c)

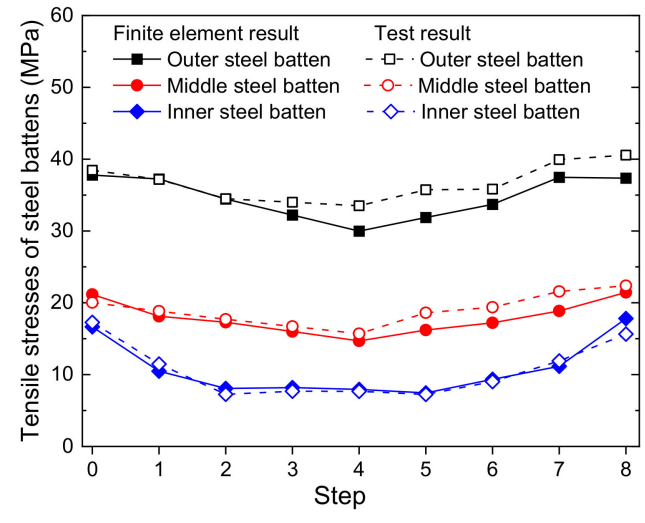

(b)

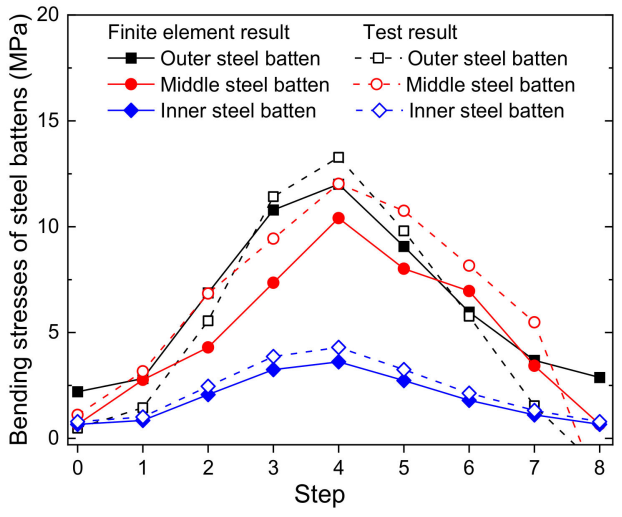

(d)

Figure 26. Stresses of the steel battens during asymmetric uniform loading. (a) Tensile stresses in the high loaded area; (b) tensile stresses in the low loaded area; (c) bending stresses in the high loaded area; (d) bending stresses in the low loaded area.

The results show that the measured values of the cable forces are in good agreement with the finite element values, and the maximum difference is $18.3 \%$. With the rising of the asymmetric uniform load, the axial forces of all cables decrease, the tensile stresses of the steel battens decrease, and the bending stresses of the steel battens increase, with almost the same variation trend as the symmetric uniform loading condition for both regions. However, when comparing the results of the two regions, it is clear that the forces of the slanting cables and the bending stresses of the steel battens in the high loaded area experienced a relatively greater ascent than those in the low loaded area. For the forces of the hoop cables, this phenomenon is not obvious.

The SBRD's vertical displacement is sensitive to the loading distribution pattern. During asymmetric uniform loading test, small upward deformations are documented at the middle struts and inner compression ring of the low loaded area, and the structure appears an overall torsion centered by the inner compression ring.

For the vertical deformations of the steel battens, the values in the high loaded area are larger than those in the low loaded area. The maximum vertical deformation occurs at the mid-span of the middle steel battens, with relatively larger values for the experimental results than for the finite element ones, and the maximum vertical difference is $3.27 \mathrm{~mm}$.

After unloading the asymmetric uniform load, the maximum displacement of the structure is larger than that before loading, which means that residual deformation exists. 


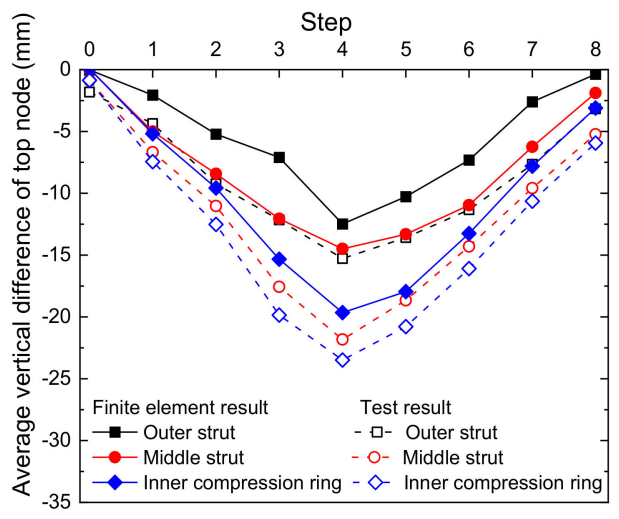

(a)

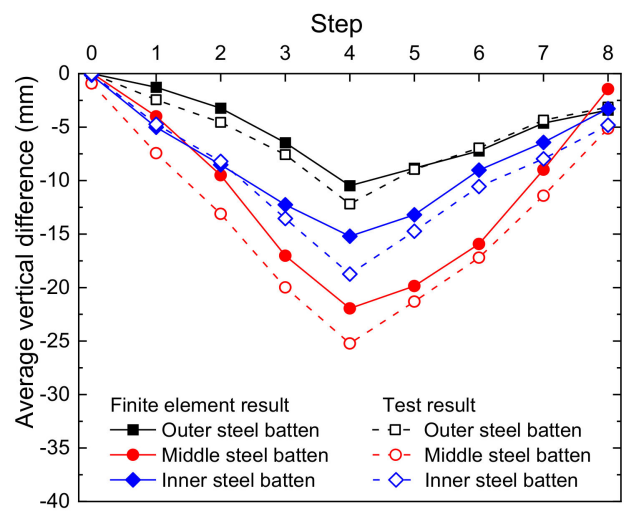

(c)

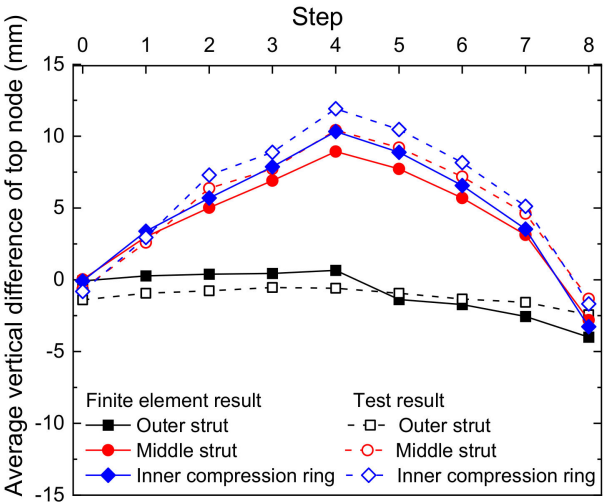

(b)

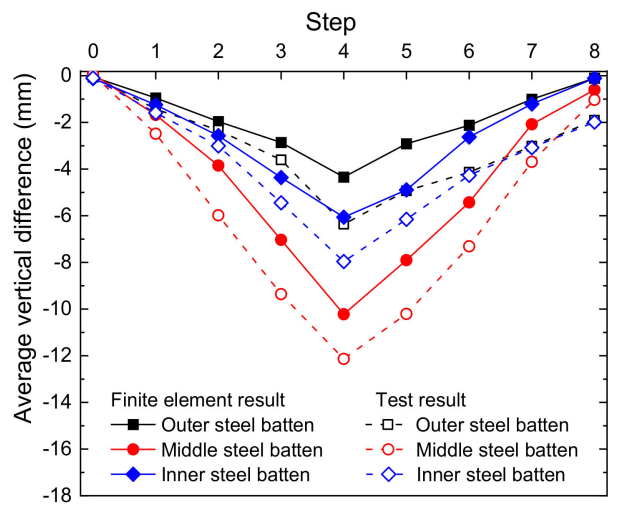

(d)

Figure 27. Average differences of the measuring nodes during symmetric uniform loading. (a) Struts in the high loaded area; (b) struts in the low loaded area; (c) segments of the steel battens in the high loaded area; (d) segments of the steel battens in the low loaded area.

\section{Conclusions}

In this study, a new type of large-span system called an SBRD is preliminary designed, which replaces the ridge cables of conventional cable domes with semi-rigid steel battens; thus, rigid roofing materials can be installed overhead. The upper steel battens are in a soft state without prestress, which makes the SBRD suitable for bracket or less-bracket construction technology. Furthermore, an $8 \mathrm{~m}$ diameter specimen is manufactured and monitored to investigate the structural behaviors in the different steps of the ' $\omega$ ' shaped less-bracket consequent hoist-dragging system and to analyze the structural responses under symmetric and asymmetric uniform load cases. The results are described as follows:

1. By using the outer ring beam as the support and the tool cables as the traction equipment, the SBRD could be assembled within a limited horizontal area of the construction site at low altitude, and extended to cover the whole roofing area after alternately lifting the steel batten grid and tensioning the outer slanting cables. The scalability of SBRD is advantageous to shorten the construction period and improve the flexibility of installation and disassembly in actual engineering.

2. In the early steps of hoist dragging, the structure establishes the prestress, accumulates stiffness, and finds its own internal force balance while the entire structure keeps the shape of a " $\omega$ " with both ends and midpoint sunken to guarantee that all the cables and struts remain suspended under the steel batten grid and to guarantee the stability of the overall configuration. As the internal force of the component increases in the following steps after demolishing the auxiliary cables, the outer slanting cables are tensioned, the prestress is gradually built, and the configuration of the entire structure 
changes from a " $\omega$ " shape to an " $\mathrm{m}$ " shape with both ends and midpoint exhibiting a convex structure. Finally, the structure reaches the molding state.

3. With increasing symmetric uniform load, the tensile stresses of the steel battens and the internal forces of all the cables gradually decrease, while the bending stresses of the steel battens increase. However, the total stresses of the steel battens do not exceed their yield strength; in this case, the steel battens are in the elastic stage during the loading steps. The measured values are basically consistent with the finite element values, and the maximum error is within $16.1 \%$ for component forces and $16.8 \%$ for deformation results.

4. The SBRD is sensitive to loading arrangements. Under an asymmetric uniform load, the high loaded area exhibits a downward deflection, while the low loaded area exhibits small upward displacements, which made the overall structure behave torsionally centered by the inner compression ring.

Author Contributions: Conceptualization, M.D., Y.S. and L.W.; data curation, Y.W. and B.L.; formal analysis, M.D. and Y.S.; funding acquisition, M.D. and B.L.; investigation, Y.W. and B.L.; methodology, Y.W.; project administration, Y.W.; resources, Y.W. and B.L.; software, M.D. and Y.S.; supervision, Y.W. and B.L.; validation, B.L.; visualization, L.W.; writing-original draft, M.D., Y.S., L.W. and N.Z.; writing-review and editing, M.D., B.L. and N.Z. All authors have read and agreed to the published version of the manuscript.

Funding: This research was funded by the National Natural Science Foundation of China, Grant Numbers 51778300 and 52108150; the Key Research and Development Project of Jiangsu Province, Grant Number BE2020703; the Natural Science Foundation of Jiangsu Province, Grant Numbers BK20190753 and BK20191390; the six talent peaks project of Jiangsu Province, Grant Number JZ017; the Natural Science Foundation of the Jiangsu Higher Education Institutions of China, Grant Number 18KJB560011; and the Priority Academic Program Development of Jiangsu Higher Education Institutions (PAPD).

Institutional Review Board Statement: Not applicable.

Informed Consent Statement: Not applicable.

Data Availability Statement: The data presented in this study are available on request from the corresponding author.

Conflicts of Interest: The authors declare no conflict of interest.

\section{References}

1. Guo, J.; Jiang, J. An algorithm for calculating the feasible pre-stress of cable-struts structure. Eng. Struct. 2016, 118, 228-239. [CrossRef]

2. Yan, X.; Yang, Y.; Chen, Z.; Ma, Q. Mechanical properties of a hybrid cable dome under non-uniform snow distribution. J. Constr. Steel Res. 2019, 153, 519-532. [CrossRef]

3. Deng, H.; Li, H.; Su, C.; Jiang, Y. Monitoring and Analyzing Displacement of Large-Span Spoke-Type Cable Structure Roof. J. Surv. Eng. 2017, 143, 06017001. [CrossRef]

4. Fu, X.; Gao, Y.; Xiao, C.; Tian, C. Horizontal Skyscraper: Innovative Structural Design of Shenzhen VANKE Center. J. Struct. Eng. 2012, 138, 663-668. [CrossRef]

5. Liu, F.; Wang, L.; Jin, D.; Wen, H. Equivalent continuum modeling of beam-like truss structures with flexible joints. Acta Mech. Sinica 2019, 35, 1067-1078. [CrossRef]

6. Liu, F.; Wang, L.; Jin, D.; Liu, X.; Lu, P. Equivalent micropolar beam model for spatial vibration analysis of planar repetitive truss structure with flexible joints. Int. J. Mech. Sci. 2020, 165, 105202. [CrossRef]

7. Shen, X.; Zhang, Q.; Lee, D.S.-H.; Cai, J.; Feng, J. Static Behavior of a Retractable Suspen-Dome Structure. Symmetry 2021, $13,1105$. [CrossRef]

8. Guo, J.; Zhu, M. Negative Gaussian Curvature Cable Dome and Its Feasible Prestress Design. J. Aerospace Eng. 2016, $29,04015077$. [CrossRef]

9. Wan, Z.; Cao, Z.; Sun, Y.; Fan, F. Pre-stressing method and structural behaviour of a Tensairity dome with multiple inflated cushions. Thin Walled Struct. 2018, 132, 585-595. [CrossRef]

10. Sibley, M.; Peña-García, A. Flat Glass or Crystal Dome Aperture? A Year-Long Comparative Analysis of the Performance of Light Pipes in Real Residential Settings and Climatic Conditions. Sustainability 2020, 12, 3858. [CrossRef] 
11. Thuillier, S.; Zang, S.-L.; Troufflard, J.; Manach, P.-Y.; Jegat, A. Modeling Bake Hardening Effects in Steel Sheets-Application to Dent Resistance. Metals 2018, 8, 594. [CrossRef]

12. Yu, F.; Leng, J. Multivariable interactions in simulation-based energy-saving glass roof designs. Sol. Energy 2020, 201, 760-772. [CrossRef]

13. Krentowski, J. Steel roofing disaster and the effect of the failure of butt joints. Eng. Fail. Anal. 2014, 45, 245-251. [CrossRef]

14. Zhao, Z.; Wu, J.; Liu, H.; Liang, B. Influence of Friction on Buckling and Dynamic Behavior of Suspen-Dome Structures. Struct. Eng. Int. 2019, 30, 262-269. [CrossRef]

15. Ruan, Y.; Luo, B.; Ding, M.; Huang, L.; Guo, Z. Theoretical and Experimental Study on the Antisliding Performance of Casting Steel Cable Clamps. Adv. Civ. Eng. 2019, 2019, 1438754. [CrossRef]

16. Ding, M.; Luo, B.; Pan, J.; Guo, Z. Experimental Study and Comparative Analysis of a Geiger-Type Ridge-Beam Cable Dome Structure. Int. J. Civ. Eng. 2018, 16, 1739-1755. [CrossRef]

17. Wang, B.; Li, Y. A theoretical study of super-span latticed shells. J. Constr. Steel Res. 1999, 51, 287-296. [CrossRef]

18. Luo, Y.; Shen, Y.; Xu, X. Construction Method for Cylindrical Latticed Shells Based on Expandable Mechanisms. J. Constr. Eng. Manag. 2007, 133, 912-915. [CrossRef] 